\title{
Operaciones de acarreo de divisas (carry trade) y sus efectos sobre la turbulencia cambiaria en Chile
}

\author{
Paulo Cox y José Gabriel Carreño
}

\section{Resumen}

En este estudio se ofrecen datos sobre la relación entre la operación de acarreo (carry trade) en pesos chilenos y las caídas de esta moneda frente a otras. Mediante el uso de un amplio conjunto de datos que contiene información del mercado cambiario a plazo local, mostramos que la especulación orientada a aprovechar los grandes diferenciales de la tasa de interés registrados en los últimos tiempos entre el peso y las monedas de los países desarrollados ha provocado varios episodios de turbulencia anormal, medidos por el coeficiente de asimetría de la distribución del tipo de cambio. De conformidad con el marco interpretativo que vincula a la turbulencia con los cambios en las posiciones a plazo de los especuladores, encontramos que la turbulencia es mayor en los períodos en que las mediciones de la incertidumbre mundial han sido especialmente altas.

Palabras clave

Monedas, Chile, tipos de cambio, inestabilidad monetaria, mercado de divisas, especulación. Clasificación JEL

E31, F41, G15, E24

Autores

Paulo Cox es Economista Superior de la División de Política Financiera del Banco Central de Chile.pcox@bcentral.cl

José Gabriel Carreño integra la Gerencia de Investigación Financiera de la División de Política Financiera del Banco Central de Chile. jcarreno@bcentral.cl 


\section{Introducción}

Entre el 15 y el 23 de septiembre de 2011, el peso chileno registró una depreciación respecto del dólar estadounidense de alrededor del 8,2\% (véase el gráfico 1). La magnitud de esta depreciación fue varias veces superior a la volatilidad diaria media del tipo de cambio para estas monedas entre 2002 y $2012^{1}$. No parece que se produjera ningún acontecimiento que afectara a algún factor fundamental de los que influyen en la relación de precio entre estas monedas como para desencadenar este ajuste tan grande y abrupto. Este cambio ocurrió durante un período de gran incertidumbre mundial en el contexto del debate sobre el límite de la deuda de los Estados Unidos, que tuvo lugar en los meses de agosto, septiembre y octubre de 2011 y que se vio magnificado por la confirmación de la Reserva Federal de que preveía un escenario de alta incertidumbre para la economía estadounidense en la semana del 20 de septiembre².

Antes de que el debate sobre el límite de la deuda desatara una mayor incertidumbre mundial y de que se registrara la acentuada depreciación, durante todo el mes de agosto de 2011 el peso chileno registró una apreciación moderada pero sostenida. Esta apreciación gradual pero constante, seguida de una gran depreciación repentina, generó coeficientes de asimetría relativamente grandes en la distribución de las variaciones diarias del tipo de cambio: el coeficiente de asimetría del tipo de cambio entre el peso chileno y el dólar estadounidense fue de 1,89 durante el tercer trimestre de 2011, cuando esto ocurrió ${ }^{3}$. Aún más importante es el hecho de que, de manera simultánea, los movimientos repentinos en las posiciones a plazo de los no residentes en el mercado de moneda nacional -basado principalmente en contratos a término sin entrega- hacia posiciones compradoras ${ }^{4}$ habían revertido su tendencia en las semanas previas y habían comenzado a orientarse hacia posiciones vendedoras (véase el gráfico 1), al tiempo que los diferenciales de la tasa de interés entre el peso chileno y el dólar estadounidense alcanzaron máximos históricos ${ }^{5}$. Si se comparan los valores del viernes 16 con los del viernes 23, se observa que las posiciones a plazo de no residentes mostraron un descenso acumulado de alrededor de 2.300 millones de dólares, con un descenso diario medio de alrededor de 570 millones de dólares. Esta reducción equivale a casi el doble de la desviación estándar de los cambios diarios en las posiciones netas a plazo de no residentes para $2011^{6}$.

\footnotetext{
Los autores desean agradecer a Nicolás Álvarez por haber proporcionado una gran cantidad de datos útiles y a dos revisores anónimos por sus valiosos comentarios. También quieren agradecer especialmente a Luis Antonio Ahumada y Andrés Alegría por su invalorable ayuda en el análisis de los datos utilizados en este estudio. Cualquier error es de exclusiva responsabilidad de los autores.

1 La desviación estándar de la variación diaria en el tipo de cambio es de 0,79 en la muestra (2000-2012). La depreciación diaria media durante este episodio fue de aproximadamente un 2,05\%, lo que corresponde a más de 2,5 desviaciones estándar.

2 El índice de incertidumbre de la política económica de los Estados Unidos, elaborado por Baker, Bloom y Davis (2015), alcanzó un nivel récord entre agosto y septiembre de 2011, cuando superó con creces, por ejemplo, el nivel alcanzado durante los ataques terroristas del 11 de septiembre de 2001. Véanse más detalles en el gráfico A1.1 del anexo o en US Daily News Index [en línea] www.policyuncertainty.com/us_daily.html.

3 Esta cifra representa el segundo registro más alto de la muestra (2002-2012). Durante el primer trimestre de 2011, la asimetría de la variación diaria en el tipo de cambio fue de 3,04. El coeficiente de asimetría mensual para septiembre de 2011 fue de 1,02, el cuarto coeficiente de asimetría más alto de toda la muestra.

4 Esto es desde la perspectiva de los bancos locales. Una posición compradora de operación de acarreo desde el punto de vista de un banco local, corresponde a una posición vendedora desde el punto de vista de un inversionista.

5 El diferencial medio de la tasa de interés fue del 5,1\% en 2011 y del 5,4\% en el tercer trimestre de ese año. Para toda la muestra de 2002-2012, el diferencial medio de la tasa de interés entre el peso chileno y el dólar estadounidense fue del $2 \%$. En el gráfico A1.3 del anexo se muestra la relación entre el diferencial de la tasa de interés a tres meses y el nivel de volatilidad del tipo de cambio para todo el período.

6 Hay que tener en cuenta que 2011 fue un año especialmente volátil en lo que respecta a las posiciones a plazo de no residentes.
} 


\section{Gráfico 1}

Tipos de cambio del peso chileno y el dólar estadounidense y posiciones a plazo de comerciantes no residentes en contratos a término sin entrega, 2011

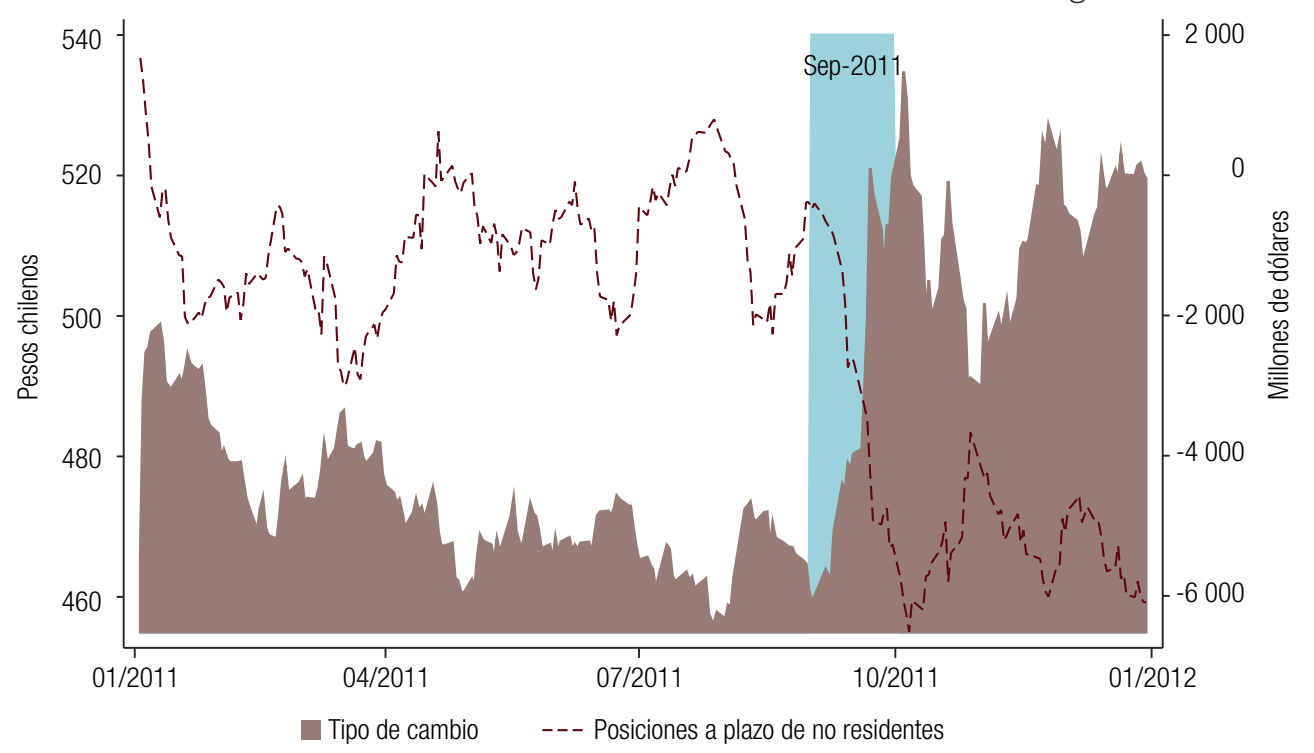

Fuente: Elaboración propia, sobre la base de información del Banco Central de Chile.

Como se documenta en el trabajo de Brunnermeier, Nagel y Pedersen (2008), los cambios en estas posiciones pueden asociarse a inversionistas que usan contratos a término en el mercado de divisas con fines especulativos: lo que popularmente se conoce como "operación de acarreo"7. Las operaciones de acarreo de divisas, como las que son de interés para este análisis, constituyen una estrategia de inversión mediante la cual los especuladores aprovechan los diferenciales de la tasa de interés entre dos monedas mediante la adopción de posiciones cortas (deuda) en una moneda con baja tasa de interés ("moneda de financiamiento") para invertir ("adoptar posiciones largas") en una moneda con una tasa de interés más alta ("moneda de inversión"). Debido a que esta estrategia no se utiliza para cubrir una depreciación del tipo de cambio ni para cubrir posiciones comerciales, la operación de acarreo se asocia a una conducta especulativa. Como ocurre con cualquier tipo de especulación, la operación de acarreo es un arma de doble filo. Por una parte, proporciona liquidez al mercado de divisas y puede acercar los precios a su nivel fundamental, con lo que mejora el rendimiento de las actividades comerciales y financieras. Por otra parte, la especulación en el tipo de cambio puede generar riesgos que no aparecerían en situaciones en que estas estrategias no pudieran aplicarse. Estos escenarios de riesgo y sus implicancias para la política monetaria se ven muy influenciados por el marco institucional y los factores económicos específicos de cada economía ${ }^{8}$.

\footnotetext{
7 La persona que realiza operaciones de acarreo es un inversionista que pide un préstamo en una moneda con baja tasa de interés e invierte en otra moneda con una tasa de interés alta. Debido a que este tipo de inversión no se realiza con fines de cobertura, se asocia a la especulación. Las operaciones de acarreo y la mayor participación extranjera en los mercados de moneda nacional son fenómenos recientes que han registrado un notable crecimiento (véase Alfaro y Kanczuk (2013)). Por supuesto que en el mercado de los contratos a término sin entrega también hay otros mecanismos que pueden usarse para realizar inversiones mediante operaciones de acarreo (agradecemos a José de Gregorio por hacernos ver este punto). Además, no solo los inversionistas extranjeros están poniendo en práctica estas estrategias, sino que los inversionistas locales también especulan. Nosotros creemos, no obstante, que las posiciones a plazo de no residentes ofrecen una mejor aproximación a las correlaciones que queremos estudiar aquí. Los distintos tipos de inversionistas son más fáciles de identificar, sobre todo en el caso chileno, mediante el análisis de las transacciones en el mercado de los contratos a término sin entrega.

8 Los últimos acontecimientos vinculados a dichas estrategias han puesto el foco especialmente en el período posterior a la crisis financiera mundial de 2008 y han alimentado las inquietudes en relación con el efecto que las bajas tasas de interés en las economías desarrolladas podrían tener sobre la estabilidad de la moneda y la eficacia de la política monetaria en los países emergentes. Véase un análisis de las implicancias de este último acontecimiento en la dirección de la política monetaria en Plantin y Shin (2011).
} 
Como muchas otras economías emergentes, la economía chilena no escapa a estos riesgos. Para evaluar los posibles riesgos (o la ausencia de estos) en el caso chileno, uno de los muchos factores por determinar es si los diferenciales de la tasa de interés, persistentemente grandes, registrados entre Chile y otras economías avanzadas en los últimos años han provocado un mayor uso de las operaciones de acarreo y, de ser así, si esto ha desatado una mayor turbulencia en el tipo de cambio o no.

Sobre la base del trabajo de Brunnermeier, Nagel y Pedersen (2008), en el presente estudio se ofrecen datos sobre las operaciones de acarreo entre el peso chileno y las principales monedas de las economías avanzadas (especialmente el dólar estadounidense) que se comercializan en el mercado cambiario local y su efecto sobre la asimetría de los cambios diarios en el tipo de cambio (nuestra medida de turbulencia). Tomando como base un conjunto de datos único de transacciones de derivados en moneda nacional en el mercado chileno, estudiamos el comportamiento de las posiciones a plazo de no residentes y establecemos las relaciones entre esas posiciones, por una parte, y los diferenciales de las tasas de interés y la asimetría de los cambios diarios en los tipos de cambio peso/dólar estadounidense y peso/euro, por la otra ${ }^{9}$. Los principales resultados de estas comparaciones son de gran interés y hasta el momento no han sido plenamente documentados.

En primer lugar, mostramos datos que revelan que el peso chileno ha estado expuesto a un riesgo de desplome: los diferenciales positivos de la tasa de interés se correlacionan con una asimetría condicional positiva de variaciones en los movimientos del tipo de cambio. En segundo término, existe una correlación que muestra una relación causal entre los movimientos en la posición neta a plazo de inversionistas extranjeros y el coeficiente de asimetría (véase el gráfico 1). Por último, mostramos que un incremento en el riesgo global o la aversión al riesgo ${ }^{10}$ coinciden con reducciones en las posiciones netas a plazo de no residentes, como lo indica la interpretación presentada en Brunnermeier, Nagel y Pedersen (2008), y Brunnermeier y Pedersen (2009) ${ }^{11}$. El riesgo de caída hace que los especuladores se abstengan de tomar posiciones lo suficientemente importantes como para revertir la paridad de la tasa de interés y moverla hacia su equilibrio, lo que, a su vez, explica el enigma de la prima a plazo (forward premium puzzle).

El resto de este artículo se encuentra organizado como se detalla a continuación. En la sección II se analiza brevemente la relación entre el enigma de la prima a plazo y las operaciones de acarreo, y se estudia cómo se ha abordado esta relación en la literatura. En la sección III describimos los datos y presentamos evidencia preliminar respecto de la relación entre las operaciones de acarreo, los movimientos de las posiciones a plazo de no residentes y el tipo de cambio. En la sección IV se presentan los resultados y la sección $\vee$ se reserva para las conclusiones.

\section{Literatura relacionada: el enigma de la prima a plazo}

Uno de los enigmas empíricos más conocidos en la literatura macroeconómica y financiera es el enigma de la prima a plazo (forward premium puzzle), que representa una violación a la paridad de tipos de interés sin cobertura ${ }^{12}$. Según la teoría económica, cuando se aplica al caso particular

9 Así, nuestro estudio complementa a otros con base en datos de operaciones extraterritoriales (este es el caso, sobre todo, respecto del estudio realizado por Brunnermeier, Nagel y Pedersen (2008)).

10 Usamos el índice VIX de volatilidad, el margen entre el Tipo Interbancario de Oferta de Londres (LIBOR) y el "swap" de tasas de interés a un día (conocido como LOIS), y el índice de incertidumbre de la política económica creado por Baker, Bloom y Davis como variables sustitutivas de la incertidumbre (2015).

${ }^{11}$ Según esta interpretación, el impacto del acontecimiento de septiembre de 2011 mencionado anteriormente no es un impacto aislado.

12 Véase un análisis de esta literatura en Hodrick (1987) y Engel (1996). 
del mercado de divisas, los especuladores en mercados sin fricciones eliminarán toda oportunidad de obtener beneficios para aprovechar los diferenciales de la tasa de interés entre dos monedas. De acuerdo con este principio, las monedas de las economías con tasas de interés altas (monedas de inversión) deberían tender a la depreciación frente a las monedas con tasas de interés más bajas (monedas de financiamiento). La falsedad de esta hipótesis, no obstante, ha sido demostrada empíricamente: en promedio, las monedas de inversión tienden a la apreciación frente a las monedas de financiamiento ${ }^{13}$.

En su trabajo seminal, donde se discute este enigma, Engel (1996) llega a la conclusión de que los modelos económicos tradicionales sin fricciones no son capaces de resolver este enigma e indica que debe considerarse seriamente la elaboración de nuevos modelos que tomen en cuenta otros fenómenos, como el llamado "problema del peso mexicano" (o "peso problema", por su denominación en inglés), los costos de transacción o el riesgo de desplome, entre otras hipótesis alternativas ${ }^{14}$.

Hasta el momento, varios autores han tratado de explicar el enigma siguiendo la recomendación de Engel. Bacchetta y Van Wincoop (2010) y Mitchell, Pedersen y Pulvino (2007) se refieren a las fricciones del mercado que pueden bloquear el arbitraje de capitales. En el primero de estos estudios se concluye que el excedente de rentabilidad derivado de las operaciones de acarreo se debe al infrecuente análisis de las decisiones de inversión por parte de los inversionistas, al tiempo que en el segundo estudio se revela que las limitaciones financieras a las inversiones de los especuladores crean situaciones donde las diferencias de precios se mantienen por largos períodos. Burnside y otros (2010) sostienen que la recompensa media positiva en una operación de acarreo sin cobertura refleja su riesgo del "problema del peso mexicano" o "peso problema"15.

Siguiendo un argumento alternativo, algunos autores señalan que la rentabilidad de las operaciones de acarreo representa una forma de compensación del riesgo de caída presente en estas estrategias (Gyntelberg y Remolona (2007), Lustig, Roussanov y Verdelhan (2008), Gromb y Vayanos (2010), y Jurek (2014)). Jurek (2014), por ejemplo, revela que la prima de riesgo de desplome representa al menos un tercio del excedente de rentabilidad en las operaciones de acarreo de divisas. De conformidad con este enfoque, Brunnermeier, Nagel y Pedersen (2008) estudian las operaciones de acarreo y desplomes de divisas en los que interviene el dólar estadounidense y aplican el marco teórico más general propuesto en Brunnermeier y Pedersen (2009) para explicar los problemas de liquidez general. En este estudio, ponemos a prueba la hipótesis planteada en Brunnermeier, Nagel y Pedersen (2008) y en Brunnermeier y Pedersen (2009). Esta hipótesis plantea que las depreciaciones repentinas y abruptas del tipo de cambio que no pueden vincularse a eventos noticiosos relacionados con factores fundamentales son causadas por la reversión de las operaciones de acarreo cuando los especuladores se acercan a sus límites de financiamiento. De acuerdo con esta hipótesis, los grandes diferenciales de la tasa de interés alientan a los especuladores a adoptar posiciones que, en ausencia de fricciones, acabarían con las oportunidades rentables. No obstante, el riesgo de desplome hace que estos mismos inversionistas se abstengan de tomar posiciones que cerrarían por completo esa ventana de beneficios.

\footnotetext{
${ }^{13}$ Bekaert y Hodrick (1992), por ejemplo, demuestran que esta hipótesis es falsa. Véase una revisión de este tema en el trabajo seminal de Fama (1984) o en la más reciente obra de Burnside y otros (2010).

${ }^{14}$ Los efectos en la inferencia de acontecimientos de baja probabilidad que no se observan en la muestra.

15 La expresión "problema del peso mexicano" o "peso problema" hace referencia a una circunstancia que es poco probable que ocurra, pero que, de ocurrir, supondría un gran cambio.
} 


\section{Datos y evidencia preliminar}

En la siguiente sección, donde se presentan los resultados de nuestra investigación, nos centraremos en el tipo de cambio del peso chileno frente a las divisas que más se utilizan en el mercado local chileno: el dólar estadounidense y el euro ${ }^{16}$. En la presente sección, no obstante, también analizaremos otras divisas, además del dólar estadounidense y el euro, para las cuales hay datos disponibles ${ }^{17}$. Recopilamos tipos de cambio nominales diarios con respecto al peso chileno y tasas de interés trimestrales para las siguientes divisas: dólar estadounidense, euro, libra esterlina, real brasileño y dólar australiano ${ }^{18}$. Estas son las divisas más utilizadas en el mercado cambiario chileno ${ }^{19}$. Consideramos el período que va desde el primer trimestre de 2002 hasta enero de 2012.

\section{Las variables}

Definimos las siguientes variables:

Logaritmo del tipo de cambio nominal $\left(s_{t}\right)$ : el tipo de cambio corresponde a la cantidad de pesos chilenos que equivalen a una unidad de moneda extranjera. El logaritmo del tipo de cambio nominal se define, entonces, como:

$$
s_{t}=\log (\text { tipo de cambio nominal })
$$

Acarreo (diferencial de la tasa de interés) $\left(i_{t}^{*}-i_{t}\right)$ : la diferencia entre $i_{t}^{*}$, que denota el logaritmo de la tasa nacional en el período $t$ (la tasa de interés extranjera desde el punto de vista de un inversionista extranjero), y $i_{t}^{*}$, que denota el logaritmo de la tasa de interés de la economía extranjera (del inversionista) (asociada a la moneda que se intercambia).

Rentabilidad de las operaciones de acarreo $\left(z_{t}\right)$ : la rentabilidad ex post de la inversión denominada en una moneda extranjera que se financia con deuda interna (en pesos), donde:

donde:

$$
z_{t+1}=i_{t}^{*}-i_{t}-\Delta s_{t+1}
$$

$\Delta s_{t+1}=s_{t+1}-s_{t}$. La rentabilidad se calcula desde la perspectiva de un comerciante no residente que invierte en pesos chilenos y financia sus posiciones en una moneda extranjera. Así, la rentabilidad final de esta estrategia se calcula en unidades de moneda extranjera.

Asimetría o coeficiente de asimetría $\left(S k e w_{t}\right)$ : el coeficiente de asimetría (tercer momento de la distribución) de la variación diaria del tipo de cambio, expresada sobre una base trimestral. Una asimetría negativa indica que la cola del lado izquierdo de la distribución de probabilidad es más larga que la del lado derecho y que el grueso de los valores se ubica a la derecha de la media de la variable (véase el gráfico 2). Una asimetría positiva, por el contrario, indica que la cola del lado derecho de

${ }^{16}$ Aproximadamente el $99 \%$ de todas las transacciones en las que participan inversionistas extranjeros en el mercado local se realizan en estas dos divisas.

${ }^{17}$ Esto nos permite analizar si las divisas con importantes diferenciales de la tasa de interés frente al peso chileno se usan como monedas de inversión o de financiamiento en las estrategias de inversión de las operaciones de acarreo. Según la hipótesis propuesta por Brunnermeier y Pedersen (2009), no deberíamos observar su uso para este propósito cuando el incentivo para llevar a cabo este tipo de estrategia de inversión es bajo.

18 Para construir los diferenciales de la tasa de interés a tres meses frente al peso chileno, usamos el tope de interés preferencial a 90 días y el Tipo Interbancario de Oferta de Londres (LIBOR) de la Asociación de Banqueros Británicos (BBA) a 90 días para el dólar estadounidense, la libra esterlina, el euro y el dólar australiano. Los tipos de cambio se obtienen de las terminales de Bloomberg.

${ }^{19}$ En una versión anterior de este estudio también incluimos el sol peruano, el peso colombiano, el dólar neozelandés, la corona noruega, el peso mexicano, el yen japonés y el dólar canadiense. Los resultados detallados en esta sección se ajustan a la inclusión de estas monedas. 
la distribución de probabilidad es más larga que la del lado izquierdo y que el grueso de los valores se ubica a la izquierda de la distribución. Un valor igual a cero indica que los valores tienen una distribución equitativa a ambos lados de la media.

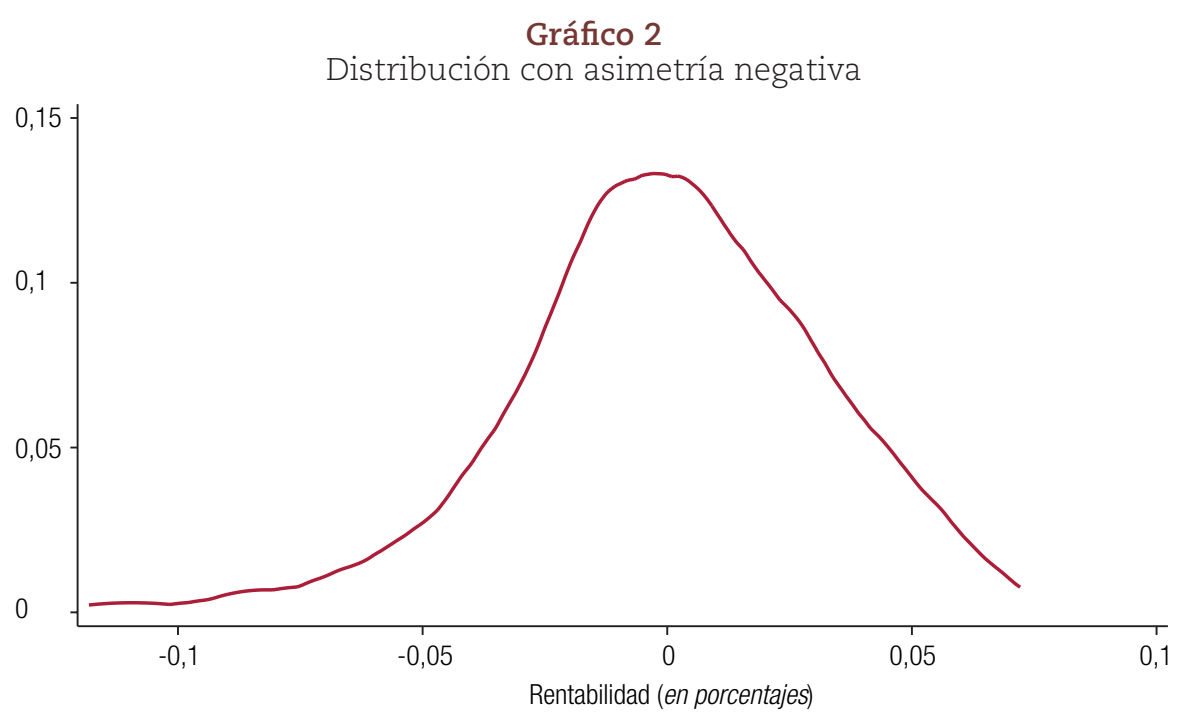

Fuente: Elaboración propia, sobre la base de información del Banco Central de Chile.

Posiciones netas de contratos a término sin entrega de no residentes $\left(F P N R_{t}\right)$ : las posiciones netas de no residentes en derivados en divisas entre las monedas extranjeras y el peso chileno usando contratos a término sin entrega ${ }^{20}$. Para esta variable contamos con información relevante solo para transacciones basadas en los tipos de cambio entre el peso chileno y el dólar estadounidense y entre el peso chileno y el euro. En este estudio, las posiciones a plazo de no residentes se analizan desde la perspectiva de los bancos locales. En consecuencia, las posiciones compradoras de no residentes representan transacciones en las que estos inversionistas compran pesos chilenos o venden dólares (los bancos chilenos, por su parte, compran dólares o venden pesos chilenos). Los valores positivos para esta variable indican que la moneda extranjera (dólar) se está usando como "moneda de financiamiento" y que la moneda nacional (peso) se está usando como "moneda de inversión".

Esta variable es la más importante de nuestro estudio y se usa como variable sustitutiva para la actividad de las operaciones de acarreo. Para construir esta variable, utilizamos información proporcionada a diario al Banco Central de Chile ${ }^{21}$ por los bancos comerciales que operan en el mercado cambiario formal ${ }^{22}$. Chile exige que todas las transacciones de derivados en divisas (principalmente los contratos a término sin entrega) sean informadas al banco central por las entidades autorizadas a realizar dichas operaciones en el mercado cambiario formal. En esos informes deben detallarse la identidad de las contrapartes, las cantidades hipotéticas, el tipo de plan de indemnización, la fecha

\footnotetext{
20 En 2013, la encuesta trienal a bancos centrales del Banco de Pagos Internacionales reveló que los contratos a término sin entrega constituyen solo la quinta parte del mercado mundial de divisas en contratos a término con un tipo de cambio fijo y una pequeña fracción del comercio global en divisas (BPI, 2013). En el caso del peso chileno, las transacciones realizadas mediante contratos a término sin entrega representan casi el 90\% de las transacciones en el mercado a plazo (Salinas y Villena, 2014).

${ }^{21}$ El banco central recopila información sobre operaciones de cambio al contado y contratos de derivados realizados por empresas bancarias y otras instituciones que pertenecen al mercado cambiario formal tanto en el mercado local como extranjero. Esta información se recopila de conformidad con el Compendio de Normas de Cambio Internacionales. Véanse más detalles sobre la profundidad, la liquidez y el tamaño del mercado cambiario formal y sus últimas novedades en Ahumada y Selaive (2007) y Salinas y Villena (2014).

22 El Banco Central de Chile publica las posiciones al final de cada mes.
} 
de vencimiento y el precio. Así, la opacidad que suele caracterizar a la información en los mercados extrabursátiles aquí no es un factor gracias a la naturaleza de las reglamentaciones de divisas en Chile 23 .

\section{Las operaciones de acarreo y la asimetría de los cambios en el tipo de cambio: datos preliminares}

En el cuadro 1 se muestran las estadísticas resumidas de las principales variables de nuestro estudio para las cinco principales monedas que se utilizan en el mercado cambiario local de derivados en divisas. Se destaca la existencia de una correlación de sección transversal positiva entre el diferencial medio de la tasa de interés $i_{t}^{*}-i_{t}$ y el excedente de rentabilidad medio $z_{t}$, lo que supone una violación de la condición de paridad de interés sin cobertura. El mayor excedente de rentabilidad medio (en dólares estadounidenses), por ejemplo, registró el mayor diferencial medio de la tasa de interés de la muestra.

Un inversionista que adoptara una posición larga de operación de acarreo en pesos chilenos, financiada con deuda en dólares estadounidenses, habría ganado el promedio trimestral del diferencial de la tasa de interés - de 0,004 (i. e. una rentabilidad anual del 1,61\%)- más un excedente de rentabilidad trimestral sobre el tipo de cambio de alrededor de 0,003 (un 1,21\% anual) durante el período cubierto por nuestra muestra. Al mismo tiempo, no obstante, el inversionista habría estado expuesto a una asimetría positiva de 0,04924.

\section{Cuadro 1}

Estadísticas descriptivas (medias): datos trimestrales, primer trimestre de 2002-primer trimestre de 2012

\begin{tabular}{lccccc}
\hline & USD & EUR & GBP & BRL & AUD \\
\hline$\Delta s_{t}$ & $-0,003$ & 0,001 & $-0,003$ & 0,001 & 0,005 \\
\hline$z_{t}$ & 0,007 & 0,002 & 0,004 & $-0,01$ & $-0,006$ \\
\hline$i_{t-1}^{*}-i_{t-1}$ & 0,004 & 0,002 & 0,001 & $-0,01$ & $-0,001$ \\
\hline Asimetría & 0,0049 & 0,113 & 0,076 & $-0,023$ & $-0,081$ \\
\hline Posiciones a plazo de no residentes & -2290 & -49 & $\ldots$ & $\ldots$ & $\ldots$
\end{tabular}

Fuente: Elaboración propia, sobre la base de información del Banco Central de Chile.

Nota: USD: Dólares estadounidenses; EUR: Euros; GBP: Libras esterlinas; BRL: Reales brasileños; AUD: Dólares australianos. $\Delta s_{t}$ es el cambio en el logaritmo del tipo de cambio (pesos chilenos por unidad de moneda extranjera). $z_{t}$, cuando el diferencial de la tasa de interés a tres meses es positivo, es la rentabilidad de la inversión en una posición larga en moneda local financiada con un préstamo en moneda extranjera. Cuando la diferencia es negativa, es lo opuesto. Las posiciones a plazo de no residentes son las posiciones netas (largas-cortas) a plazo de no residentes, en miles de millones de pesos, considerando únicamente los contratos a término sin entrega; los datos de posiciones a plazo de no residentes son para dólares estadounidenses desde el primer trimestre de 2003. Los datos para euros son para el período que comienza en el segundo trimestre de 2006. Una posición neta a plazo de no residentes positiva implica que, en el agregado, los no residentes asumen compromisos de compra de pesos chilenos para realizar operaciones de acarreo.

En la última fila del cuadro 1 se detallan las posiciones a plazo de no residentes. Una posición negativa supone que, en el agregado, los especuladores tienen una posición vendedora neta en dólares, mientras que las posiciones positivas implican que este grupo de inversionistas constituye un

23 Durante la mayor parte del período considerado en nuestro estudio, las posiciones a plazo agregadas de no residentes fueron negativas, lo que indica que, en términos agregados, la variable de las posiciones a plazo de no residentes no refleja la puesta en marcha de estrategias de operaciones de acarreo. No obstante, lo que aquí nos interesa es el cambio en estas posiciones.

24 Del cuadro 1 se desprende que el grueso de las transacciones "especulativas" (que involucran a inversionistas extranjeros) se realiza entre el peso chileno y el dólar estadounidense, con un volumen más pequeño de transacciones en las que intervienen el peso chileno y el euro. En las siguientes secciones de este estudio no se hará referencia a otras monedas, debido a que las transacciones con estas monedas son muy esporádicas. 
comprador neto. Si las posiciones estuvieron mayormente compuestas de operaciones de acarreo, las posiciones netas a plazo de no residentes serían positivas, en promedio. Esto no es lo que se observa en el cuadro 1. Hay otras transacciones además de las especulativas, como las de cobertura, por ejemplo, que opacan las transacciones de operaciones de acarreo. Como ya se mencionó, no obstante, lo que aquí nos interesa no es el nivel de las posiciones a plazo de no residentes, sino el cambio en estas posiciones de un período a otro y la relación entre estos cambios, por una parte, y los diferenciales de la tasa de interés y el coeficiente de asimetría, por la otra.

Sobre la base de la información del cuadro 1, en el gráfico 3 se muestra la relación entre la operación de acarreo, su rentabilidad (véase el gráfico 3A) y el coeficiente de asimetría (véase el gráfico $3 \mathrm{~B})^{25}$. De conformidad con la condición de paridad de interés sin cobertura, la rentabilidad media debe ser cero. No obstante, entre los diferenciales medios de la tasa de interés y el excedente de rentabilidad existe una correlación positiva que viola esa condición (gráfico 3A). Esta relación se ajusta al trabajo de Jurek (2014) que, usando una muestra de las divisas del Grupo de los 10 (G10), encuentra que la operación de acarreo de divisas genera grandes excedentes de rentabilidad, con ratios de Sharpe anuales equivalentes o superiores a los de los mercados de acciones (1900-2012). Los datos presentados en el cuadro 1 y el gráfico 3B también indican que existe una relación positiva entre la asimetría y los diferenciales medios de la tasa de interés. Esta correlación positiva implica que la operación de acarreo está sujeta a una asimetría positiva (riesgo de caída), i. e. el peso chileno está expuesto a una fuerte depreciación respecto del dólar estadounidense y otras monedas. En el cuadro 1 también se destaca que el coeficiente de asimetría es negativo para aquellas monedas en las que el diferencial de la tasa de interés es negativo, como el real brasileño y el dólar australiano. Esto coincide con la interpretación presentada por Brunnermeier y Pedersen (2009).

\section{Gráfico 3}

Diferenciales de sección transversal de rentabilidad empírica, asimetría y tasa de interés a tres meses, datos trimestrales, primer trimestre de 2002-primer trimestre de 2012

\section{A. Rentabilidades \\ (En porcentajes)}

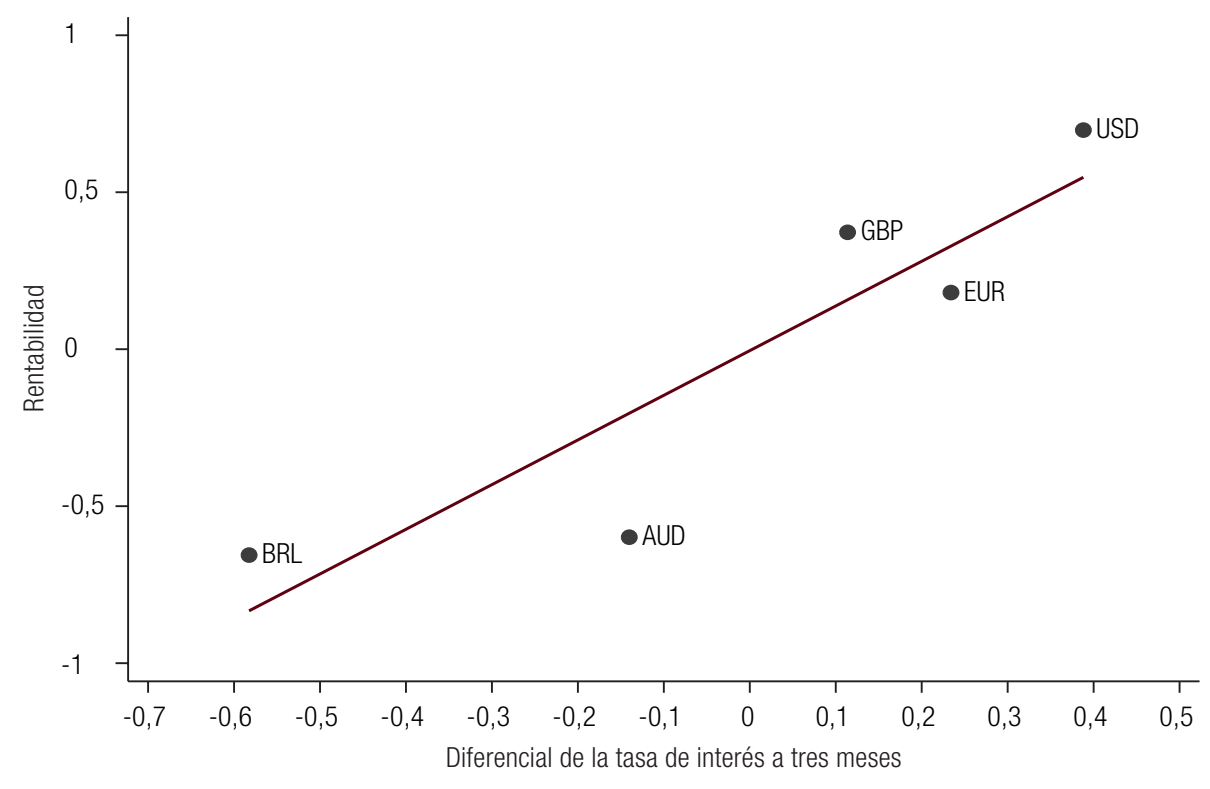

25 Véanse más detalles sobre todos los valores observados, por moneda y trimestre, en los gráficos A1 y A2 del anexo. 
Gráfico 3 (conclusión)

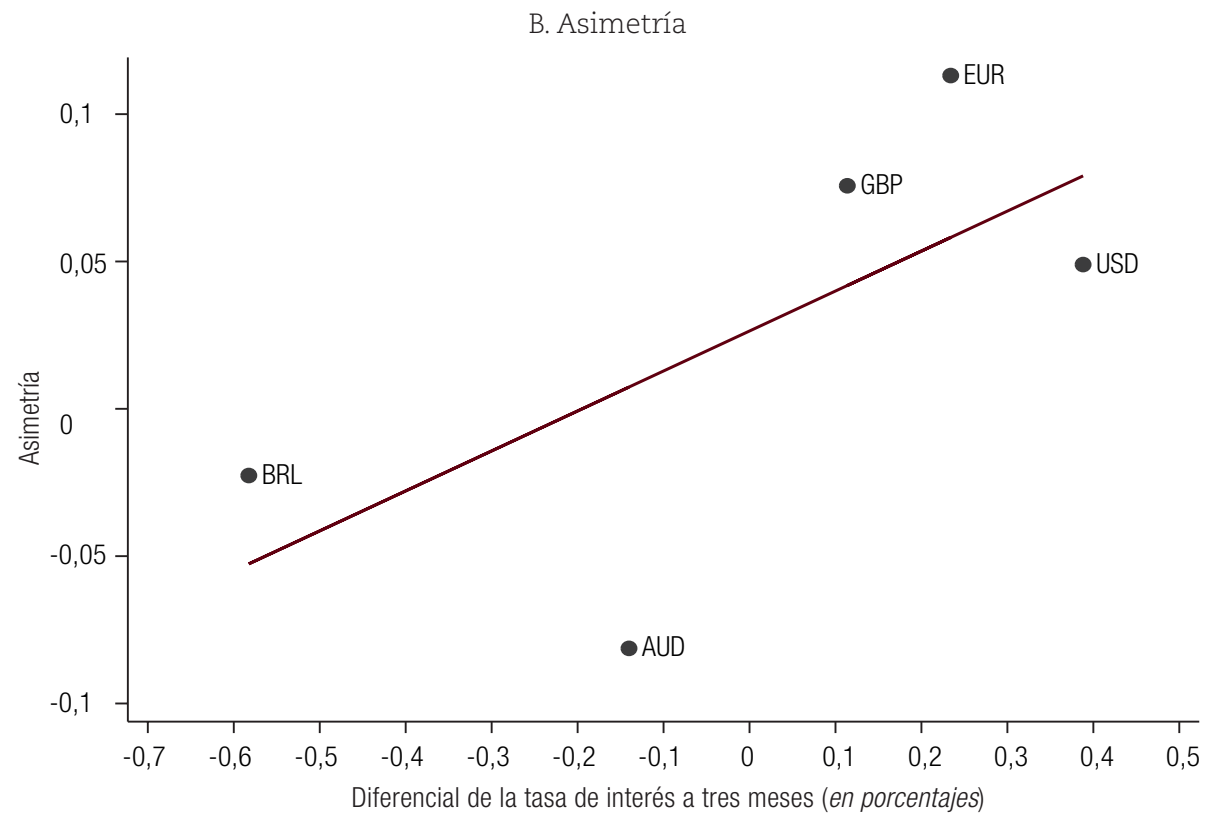

Fuente: Elaboración propia, sobre la base de información del Banco Central de Chile.

Nota: USD: Dólares estadounidenses; EUR: Euros; GBP: Libras esterlinas; BRL: Reales brasileños; AUD: Dólares australianos.

Otra forma de obtener datos sobre los excedentes de rentabilidad y su correlación con el coeficiente de asimetría es mediante el análisis de la distribución del excedente de rentabilidad $z_{t}$ dependiendo de los diferenciales de la tasa de interés $i_{t-1}^{*}-i_{t-1}$ (véase el gráfico 4), con las observaciones agrupadas de acuerdo con los siguientes rangos de diferenciales: $i_{t-1}^{*}-i_{t-1} \leq-0,0035$; $-0,0035 \leq i_{t-1}^{*}-i_{t-1} ; \mathrm{y} i_{t-1}^{*}-i_{t-1} \geq-0,0035$.

Del gráfico 4 se desprende que, en el caso de importantes diferenciales de la tasa de interés (línea punteada azul), la distribución del excedente de rentabilidad es, en promedio, positiva y exhibe una larga cola del lado izquierdo, lo que revela la asimtetría del cambio en el tipo de cambio (asimetría) ${ }^{26}$. Cuando los diferenciales de la tasa de interés son negativos, en cambio, no observamos asimetría en la distribución de la rentabilidad, ya que, para estas monedas, el incentivo de realizar operaciones de acarreo con el peso chileno es menor, como ocurre en el caso del real brasileño. En lo que respecta a diferenciales de la tasa de interés próximos a cero, vemos que la distribución se centra en cero y es simétrica. Todo esto confirma la existencia de un riesgo de desplome en las transacciones de operación de acarreo.

Los datos aquí proporcionados para un corte transversal de monedas, en suma, apuntan a una relación positiva entre los diferenciales de la tasa de interés y el riesgo de caída de la moneda. Estos resultados, no obstante, corresponden a correlaciones entre variables que pueden estar sistemáticamente relacionadas o no. En el análisis que se plantea a continuación se aprovechan las series cronológicas y se agrega información sobre transacciones de los especuladores con el propósito de demostrar empíricamente la hipótesis planteada por Brunnermeier y Pedersen (2009).

26 Tanto el dólar estadounidense como el euro pertenecen a este grupo. 


\section{Gráfico 4}

Distribución de Kernel de la rentabilidad $z_{t}$ como una función de los diferenciales de la tasa de interés (tras eliminar efectos fijos), primer trimestre de 2002-primer trimestre de 2012

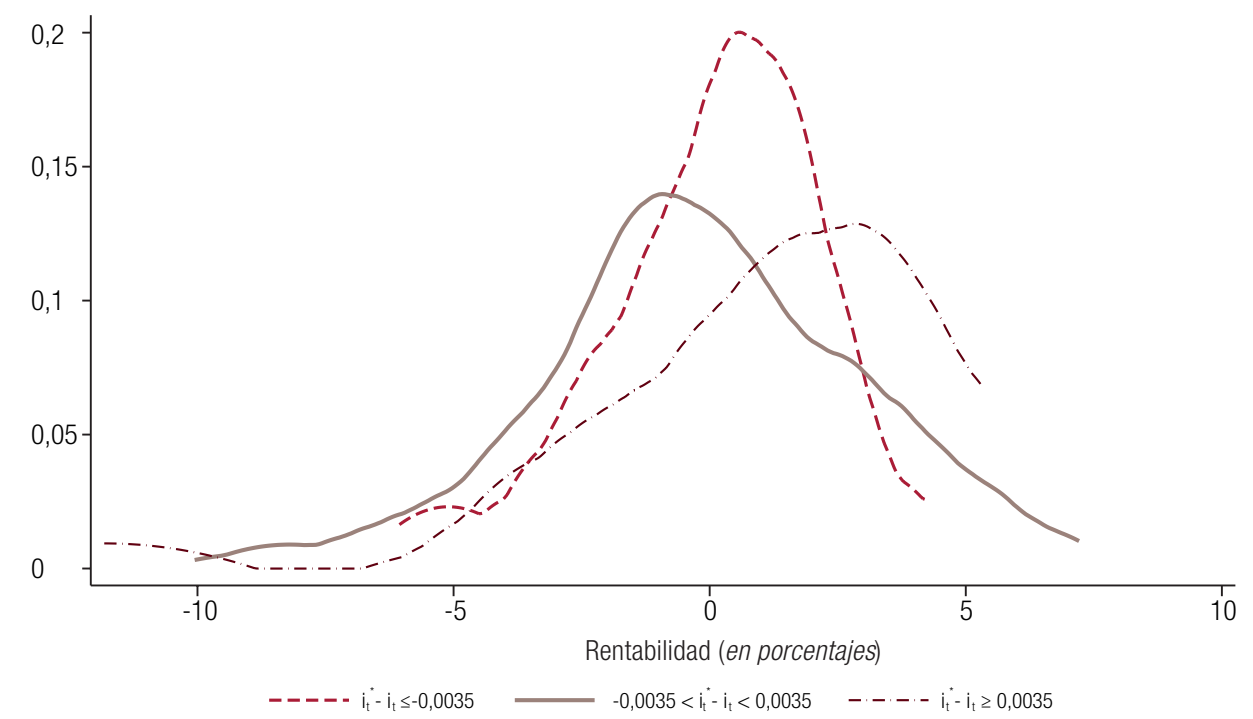

Fuente: Elaboración propia, sobre la base de información del Banco Central de Chile.

Nota: Los datos corresponden al dólar estadounidense, el euro, la libra esterlina, el dólar australiano, el real brasileño, el sol peruano, el peso colombiano, el dólar neozelandés, la corona noruega, el peso mexicano, el yen japonés y el dólar canadiense.

\section{Resultados}

\section{La relación entre las operaciones de acarreo de divisas y las turbulencias en el tipo de cambio}

Comenzamos por estudiar los predictores de grandes correcciones en el tipo de cambio. En particular, nos centamos en los diferenciales de la tasa de interés y la actividad de las operaciones de acarreo. Como variable sustitutiva del riesgo de desplome, usamos el coeficiente de asimetría $\left(S k e w_{t}\right)$, la variable dependiente. Mediante el uso de regresiones lineales simples, probamos si el coeficiente de las posiciones a plazo de no residentes y los retardos de la variable dependientes son predictores significativos del riesgo de caída en relación con el tipo de cambio. Un incremento en los diferenciales de la tasa de interés tiene una incidencia positiva en el riesgo de caída. Por lo tanto, esperamos un signo positivo para este coeficiente. Una posición a plazo compradora de no residentes (actividad de operaciones de acarreo con el peso chileno), además, incrementa el riesgo, por lo que también esperamos un signo positivo en este coeficiente. Por último, esperamos un signo positivo en el coeficiente de la variable dependiente rezagada, ya que un mayor nivel de riesgo en el pasado desalentaría las posiciones cortas muy agresivas en el presente.

Específicamente, consideramos las siguientes regresiones de panel:

$$
\operatorname{Skew}_{j t+1}=\beta_{1} \operatorname{Skew}_{j t}+\beta_{2}\left(i_{j t}^{*}-i_{j t}\right)+\beta_{3} F P N R_{j t}+\beta_{4} X_{j t}+\alpha_{j}+\varepsilon_{j t}
$$

donde $j$ es un determinado país y $t$ un determinado trimestre. $X_{j t}$ es un vector de control que, dependiendo de la especificación, puede incluir: $z_{j t}$, la rentabilidad de la operación de acarreo; $B C C H_{t}$, una variable ficticia que toma el valor de $1 \mathrm{si}$, en el trimestre correspondiente, el banco 
central anunció una intervención en la moneda o intervino en el mercado cambiario, y el valor de 0 si no lo hizo; $\log$ (Copper), el logaritmo del precio del cobre (centavos de dólares estadounidenses/ libra) informado en la Bolsa de Metales de Londres; $\log ($ Oil $)$, el logaritmo del precio nominal del petróleo informado en la Bolsa Mercantil de Nueva York (NYMEX); el índice de bonos de mercados emergentes (EMBI), que es el promedio ponderado de primas de riesgo soberano para un amplio grupo de economías emergentes y tiene por objeto controlar los cambios en el riesgo de un país; $\mathrm{y}$, por último, $\alpha_{j}$ y $\varepsilon_{j t}$, que corresponden al efecto fijo de la moneda y el error, respectivamente. Los resultados se muestran en el cuadro $2^{27}$. En las primeras tres columnas del cuadro 2 se muestra que las operaciones de acarreo $\left(i_{t}^{*}-i_{t}\right)$ son un fuerte predictor de la asimetría futura. También se verifica que el retardo de la variable Skew tiene un coeficiente negativo, lo que indica una reversión a la media en esta variable. Además, el coeficiente de las posiciones a plazo de no residentes se relaciona positivamente con la asimetría futura.

Cuadro 2

Predictores de caída de la moneda

\begin{tabular}{|c|c|c|c|c|}
\hline & $S_{k e w_{t+1}}$ & $S k e w_{t+1}$ & $S k e w_{t+1}$ & Risk Reversal $_{t}$ \\
\hline \multirow{2}{*}{$i_{t-1}^{*}-i_{t-1}$} & $57,34^{\star \star \star}$ & $57,07^{\star \star \star}$ & $53,31^{\star \star \star}$ & $113,9^{\star \star \star}$ \\
\hline & $(13,22)$ & $(12,82)$ & $(0,501)$ & $(9,182)$ \\
\hline \multirow{2}{*}{$F P N R_{t}$} & $0,0373^{\star \star *}$ & $0,0304^{\star \star *}$ & $0,128^{\star \star \star}$ & $-0,257^{\star * \star}$ \\
\hline & $(0,00153)$ & $(0,00924)$ & $(0,0443)$ & $(0,0148)$ \\
\hline \multirow{2}{*}{ Skew $_{t}$} & $-0,148^{\star \star \star}$ & $-0,151^{\star \star \star}$ & $-0,186^{\star \star \star}$ & $-0,461^{\star \star *}$ \\
\hline & $(0,0248)$ & $(0,0154)$ & $(0,0415)$ & $(0,0688)$ \\
\hline \multirow{2}{*}{$\mathrm{BCCH}_{t}$} & $0,848^{\star \star \star}$ & $0,831^{\star \star \star}$ & $0,765^{\star \star \star}$ & $-0,618^{\star \star \star}$ \\
\hline & $(0,0609)$ & $(0,0369)$ & $(0,0745)$ & $(0,0334)$ \\
\hline \multirow{2}{*}{$z_{t}$} & & 2,651 & 1,631 & $-14,57^{\star \star \star}$ \\
\hline & & $(3,016)$ & $(1,092)$ & $(2,545)$ \\
\hline \multirow{2}{*}{$\log ($ Copper $)$} & & & $0,338^{\star \star \star}$ & $-0,560$ \\
\hline & & & $(0,119)$ & $(0,836)$ \\
\hline \multirow{2}{*}{$\log (O i l)$} & & & $-0,108$ & $1,842^{\star \star *}$ \\
\hline & & & $(0,119)$ & $(0,448)$ \\
\hline \multirow{2}{*}{ EMBI } & & & $-0,176$ & $1,258^{\star \star \star *}$ \\
\hline & & & $(0,427)$ & $(0,130)$ \\
\hline Observaciones & 62 & 62 & 62 & 51 \\
\hline $\mathrm{R}^{2}$ & 0,240 & 0,254 & 0,304 & 0,531 \\
\hline
\end{tabular}

Fuente: Elaboración propia, sobre la base de información del Banco Central de Chile y datos de Bloomberg.

Nota: Regresiones de panel con efectos fijos del país y datos trimestrales para el período entre el primer trimestre de 2002 y el primer trimestre de 2012. Los datos de las posiciones a plazo de no residentes (FPNR) incluyen únicamente los contratos a término sin entrega, en miles de millones de dólares. Las reversiones del riesgo (Risk Reversal) son la diferencia de volatilidad implícita entre la opción de compra de moneda extranjera a un mes y las opciones de venta. Los datos de panel son para dólares estadounidenses a partir del primer trimestre de 2002 y para euros a partir del segundo trimestre de 2006. Los datos de reversión del riesgo son para dólares estadounidenses a partir del primer trimestre de 2005 y para euros a partir del tercer trimestre de 2006 . Los errores estándar agrupados se muestran entre paréntesis: ${ }^{\star * \star} p<0,01 ;{ }^{\star *} p<0,05 ;{ }^{*} p<0,1$.

Hemos incluido una variable ficticia en todas las especificaciones para la intervención del banco central, lo que es positivo y significativo. Se ha demostrado que los anuncios o las intervenciones del banco central incrementan el riesgo de desplome de la moneda. En la medida en que los incrementos

\footnotetext{
27 Para facilitar la lectura e interpretación de los coeficientes de las posiciones a plazo de no residentes en el cuadro 2, hemos expresado esta variable en miles de millones de dólares. En el resto del artículo, esta variable se expresa en millones de dólares.
} 
en Skew $_{t+1}$ debido a estos anuncios resultan en un menor grado de especulación, este resultado es útil para el control de la turbulencia del tipo de cambio, pero debe analizarse más en profundidad.

Destacamos que todos estos resultados coinciden con los datos indicados en las secciones anteriores. En la segunda columna del cuadro 2 se muestra que la rentabilidad de la moneda, $z_{t}$, tiene el signo esperado (las rentabilidades positivas de las operaciones de acarreo llevan a los inversionistas a adoptar posiciones), aunque el coeficiente no es significativo, posiblemente debido a que el coeficiente de las posiciones a plazo de no residentes tiene una fuerte correlación con la rentabilidad.

Cabe destacar que la relación entre el coeficiente de las posiciones a plazo de no residentes y el coeficiente de asimetría es robusta respecto de la inclusión de factores fundamentales que usualmente se incluyen en modelos a largo plazo para el tipo de cambio del peso chileno y el dólar estadounidense, como el precio del cobre, el precio del petróleo y el EMBI. De estas tres variables, el precio del cobre es la única variable de control que es estadísticamente significativa cuando se hace una regresión de la asimetría del tipo de cambio ${ }^{28}$.

Como otra marca de robustez, incluimos la variable de reversión del riesgo (en la última columna del cuadro 2) como una variable dependiente alternativa del riesgo de desplome. La reversión del riesgo es una medición de la volatilidad implícita en la diferencia entre una opción de compra de moneda extranjera a un mes y una opción de venta de moneda extranjera a un mes ${ }^{29}$. El precio, entonces, refleja el costo de la cobertura de seguro para los cambios en el tipo de cambio. Cuanto mayor sea el riesgo de caída, mayor será el precio. Como era de esperar, tanto la variable de acarreo como la variable de asimetría rezagada son significativas y tienen los signos previstos. El coeficiente de las posiciones a plazo de no residentes es negativo y significativo. Por lo tanto, tiene el signo opuesto al teórico, posiblemente debido a que el efecto de un mayor acarreo sobre esta variable en el período $t$ ya ha sido captado por el diferencial de la tasa de interés. Estos resultados son similares a los expuestos por Hutchison y Sushko (2013), quienes dan cuenta de un vínculo estrecho entre las reversiones del riesgo y las posiciones especulativas en el mercado de futuros en el yen japonés. Algo similar ocurre con la rentabilidad $z_{t}$.

Tras haber establecido las relaciones empíricas entre las operaciones de acarreo, la asimetría y las posiciones a plazo de no residentes, en el siguiente apartado se analiza en detalle la relación dinámica entre estas tres variables usando un modelo de autorregresión vectorial.

\footnotetext{
${ }^{28}$ El hecho de que el peso chileno se considere un dinero mercancía indica que en el episodio descrito en la Introducción debe tomarse en cuenta la tendencia de este factor fundamental. De hecho, el precio del cobre, que es el principal factor detrás de la tendencia del tipo de cambio del peso chileno y el dólar estadounidense, tanto a corto como a largo plazo, se depreció alrededor de un $12 \%$ durante este episodio (véase la Introducción). No obstante, no hay que olvidar que este precio también se ve afectado por la incertidumbre mundial. Parece poco probable, de hecho, que la incertidumbre en los Estados Unidos se deba a noticias referidas al precio del cobre durante este episodio. En Wu (2013) pueden obtenerse datos respecto del papel del cobre en los recientes desajustes del tipo de cambio. Wu identifica varios episodios recientes en los que algunos factores fundamentales, en especial el precio del cobre, no son suficientes para explicar las distorsiones en los cambios a corto plazo del tipo de cambio. Los datos dados a conocer en este estudio respaldan esos hallazgos, ya que indican que los desajustes identificados en el tipo de cambio se deben a la turbulencia provocada por las operaciones de acarreo de dólares estadounidenses y pesos chilenos.

${ }^{29}$ En el cuadro 2 se muestra un menor número de observaciones para la especificación usando la reversión del riesgo como la variable dependiente. Esto se debe a la disponibilidad de los datos.
} 


\section{Modelo de autorregresión vectorial: el caso de la operación de acarreo entre el peso chileno y el dólar estadounidense}

En esta sección estimamos un modelo de autorregresión vectorial de segundo orden centrándonos exclusivamente en transacciones con dólares estadounidenses. Este análisis nos permite estudiar la relación sistemática y dinámica entre el diferencial de la tasa de interés, la rentabilidad de la operación de acarreo, las posiciones de los especuladores (posiciones a plazo de no residentes) y el coeficiente de asimetría en el contexto de la operación de acarreo entre el peso chileno y el dólar estadounidense. Usamos datos mensuales para el período que va del primer mes de 2002 al primer mes de 2012. Los choques subyacentes a la función de impulso-respuesta se apoyan en una descomposición de Cholesky basada en el siguiente orden: $i_{t}^{*}-i_{t}, z$, Skewness y posiciones a plazo de no residentes ${ }^{30}$. Todas las variables se filtran usando el método de Hodrick y Prescott para la descomposición de los componentes cíclicos de la serie.

En el gráfico 5 se muestra el impulso-respuesta de un choque de una desviación estándar sobre el diferencial de la tasa de interés, usando intervalos de confianza del 95\%. En el gráfico 5C se observa que el coeficiente de las posiciones a plazo de no residentes se encuentra estrechamente relacionado con el diferencial de la tasa de interés (gráfico 5A). Los amplios márgenes llevan a una mayor actividad de operaciones de acarreo, lo que se ve impulsado por un incremento de la rentabilidad prevista para los inversionistas que usan el peso chileno como moneda de inversión y el dólar estadounidense como moneda de financiamiento.

El aumento en las transacciones de operaciones de acarreo tiene dos efectos sobre la asimetría $\left(\right.$ Skew $\left._{t}\right)$. Por una parte, genera una apreciación del tipo de cambio, y, por la otra, esta apreciación produce un riesgo de desplome. Esto último se refleja en el aumento de la probabilidad de ajustes abruptos en el tipo de cambio (un incremento en la asimetría positiva). De hecho, el grueso de la distribución de los cambios en el tipo de cambio se traslada hacia eventos de apreciación, al tiempo que la cola del lado derecho de la distribución se ensancha, debido a que el aumento en los eventos de riesgo de caída tiene una frecuencia más baja pero una magnitud más grande. Este efecto de mayor asimetría es provocado por una liquidación (reversión) de posiciones especulativas, que, a su vez, provoca un "espiral de pérdidas". El aumento del riesgo de desplome hace que los inversionistas compensen posiciones o no inviertan tanto como antes del choque. En el gráfico 5D se muestra que, a medida que el volumen de las transacciones de operaciones de acarreo aumenta (véase el gráfico $5 \mathrm{C}$ ), primero observamos un aumento del coeficiente de asimetría, seguido de un descenso gradual que converge hacia niveles previos al choque a medida que las posiciones de los especuladores retroceden hasta su nivel inicial.

Al interpretar los resultados del modelo de autorregresión vectorial, es importante tener presente que el impacto de la operación de acarreo en el tipo de cambio probablemente sería mucho mayor si lo condicionáramos a los períodos donde se registró una mayor actividad de operaciones de acarreo (aquellos períodos, por ejemplo, en que los diferenciales de la tasa de interés fueron particularmente grandes). Durante gran parte del período analizado -entre 2002 y mediados de 2007-, los derivados en divisas no se utilizaron mucho, probablemente porque en ese momento no eran una inversión atractiva. Durante todo el período, este efecto tiende a reducir el impacto captado por un modelo de autorregresión vectorial incondicional en la totalidad de la muestra.

30 Este orden coincide con la teoría de Brunnermeier y Pedersen (2009), en la que se basa nuestra principal hipótesis de trabajo. 


\section{Gráfico 5}

Funciones de impulso-respuesta de un modelo de autorregresión vectorial (2) para un choque de una desviación estándar para diferenciales de la tasa de interés, primer mes de 2002-primer mes de 2012

$$
\text { A. Impulso }
$$

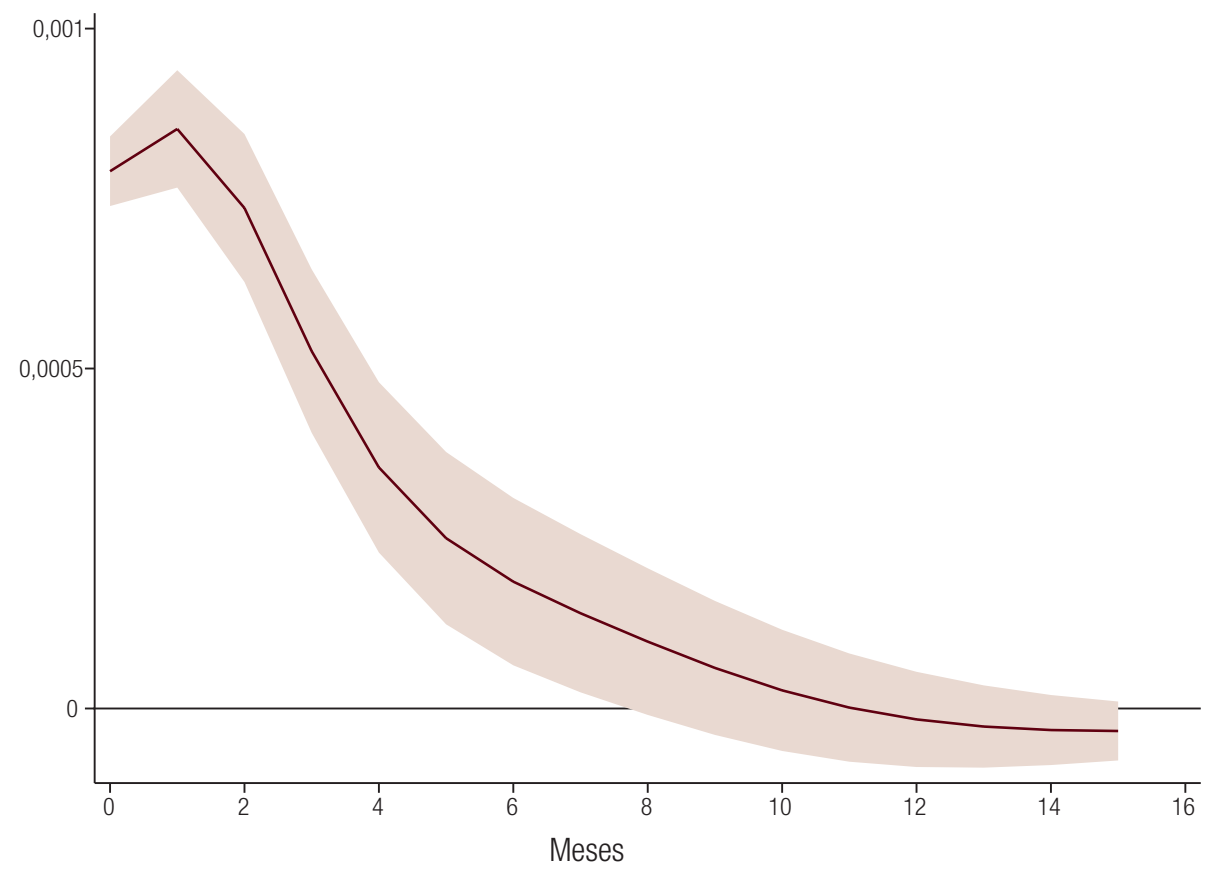

B. Rentabilidad de la operación de acarreo

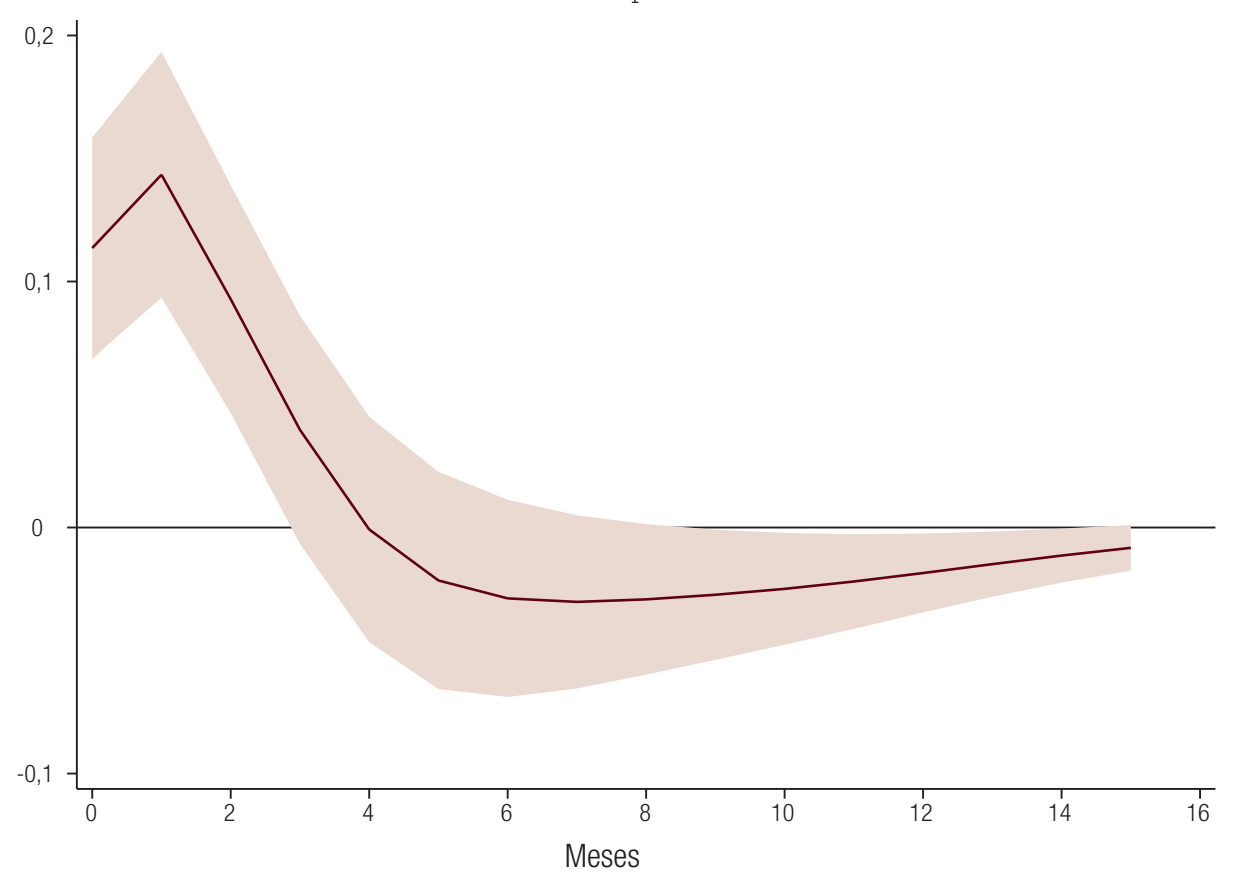


Gráfico 5 (conclusión)

C. Posiciones a plazo de no residentes

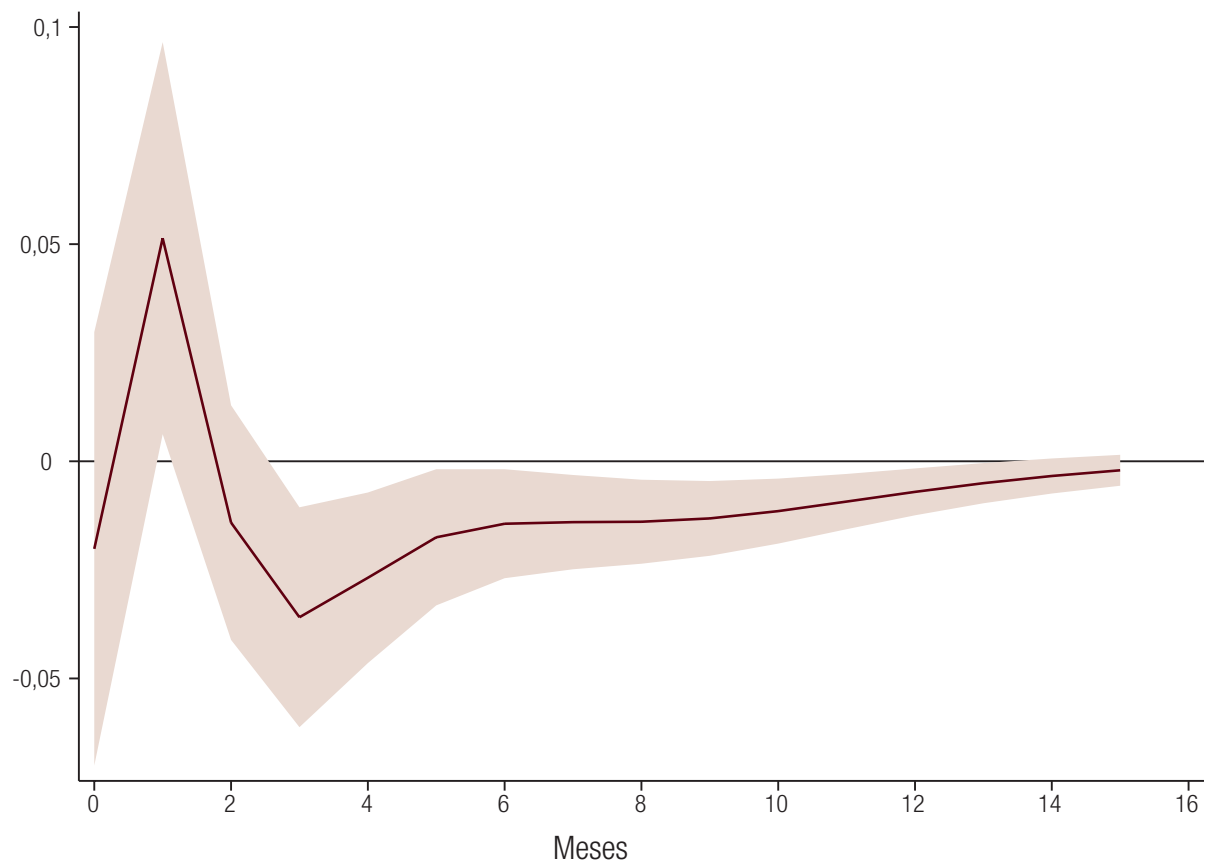

D. Asimetría

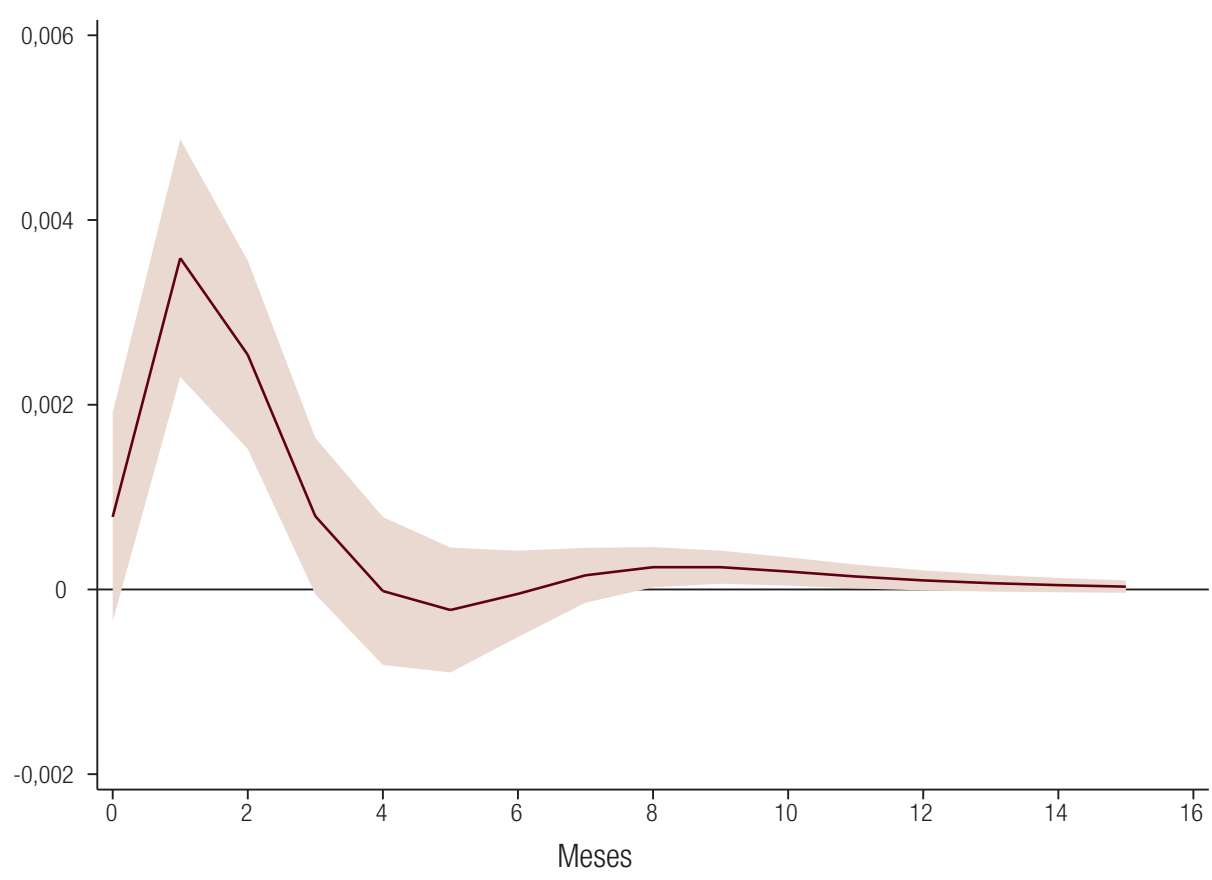

Fuente: Elaboración propia, sobre la base de información del Banco Central de Chile. 


\section{El riesgo de liquidez y la reversión de las operaciones de acarreo}

En este apartado, analizaremos más detalladamente la conducta de los especuladores. Específicamente, revisaremos los factores que llevan a los especuladores a revertir sus posiciones, como las pérdidas repentinas en sus posiciones, el aumento en los márgenes de financiamiento o la reducción de su tolerancia al riesgo. Con esta finalidad, usamos dos medidas para la incertidumbre agregada, que normalmente se asocian con la iliquidez de financiamiento y la aversión al riesgo de los inversionistas: i) el índice de volatilidad del mercado de opciones de Chicago (CBOE VIX), y ii) el índice de incertidumbre de la política económica creado por Baker, Bloom y Davis (2015). Ambas medidas de incertidumbre se utilizan como variables sustitutivas observables que deben correlacionarse con los factores mencionados anteriormente (por ejemplo, véanse los determinantes macroeconómicos de la actividad de las operaciones de acarreo en Anzuini y Fornari (2011)). Informamos los resultados utilizando solo el índice de incertidumbre de la política económica ${ }^{31}$. Consideramos las siguientes regresiones de panel:

$$
\Delta P F N R_{j t}=\beta_{1} \Delta E P U_{t} \times \operatorname{sign}\left(i_{j t-1}^{*}-i_{t-1}\right)+\beta_{2} E P U_{t}+\beta_{3} F P N R_{j t-1}+\beta_{4} B C C H_{t}+\alpha_{j}+\varepsilon_{j t}(2)
$$

y

$$
\Delta z_{j t}=\beta_{1} \Delta E P U_{t} \times \operatorname{sign}\left(i_{j t-1}^{*}-i_{t-1}\right)+\beta_{2} E P U_{t}+\beta_{3} B C C H_{t}+\alpha_{j}+\varepsilon_{j t}
$$

donde $j$ es el país, $t$ es tiempo, $\alpha_{j}$ representa el efecto fijo del país (o la moneda) y $\varepsilon_{j t}$ es el término perturbador. El signo esperado para el coeficiente de la variable de interacción que se obtiene de multiplicar el índice de incertidumbre de la política económica y la operación de acarreo, en virtud de la hipótesis de que hay una reversión de posiciones que afecta el riesgo de caída, es negativo en ambas regresiones. Hasta ahora, hemos ignorado la dirección de la operación de acarreo, dado que los diferenciales de la tasa de interés y otras variables cambian de signo cuando cambia la dirección de la operación de acarreo. Este no es el caso del índice VIX ni del índice de incertidumbre de la política económica, por lo que hacemos que estas dos variables interactúen con el signo de los diferenciales de la tasa de interés, $\operatorname{sign}\left(i_{t-1}^{*}-i_{t-1}\right)^{32}$.

Estimamos las especificaciones en las ecuaciones 2 y 3 mediante el estimador de efectos fijos. En el cuadro 3 se presentan los resultados para el índice de incertidumbre de la política económica. En las primeras dos columnas se muestra que el impacto de una mayor incertidumbre mundial en los cambios contemporáneos en las posiciones a plazo de no residentes (mismo mes) es positivo. Esto se invierte al mes siguiente, como es de esperar en un contexto donde un incremento de la incertidumbre mundial provoca una reversión de las posiciones de las operaciones de acarreo. Esto implica que los escenarios de mayor incertidumbre mundial pueden generar un riesgo de desplome, pero con cierto rezago. El hecho de que el efecto contemporáneo sobre las posiciones a plazo de no residentes sea positivo (columna 1 del cuadro 3) no se ajusta a la hipótesis de Brunnermeier y Pedersen (2009). Nuestra explicación de este resultado aparentemente confuso es la siguiente. Los choques que aumentan la incertidumbre llevan a los inversionistas no especuladores a adoptar posiciones para cubrir sus inversiones impulsadas por factores fundamentales ante una mayor volatilidad del tipo de cambio. Los lectores recordarán que las posiciones a plazo de no residentes

\footnotetext{
${ }^{31}$ Los resultados en los que se utiliza el índice VIX se incluyen en el cuadro A1.1 del anexo y coinciden con los que aquí se detallan.

32 Por supuesto, esto solo es significativo cuando el signo de acarreo cambia. Si bien la frecuencia de la ocurrencia de este evento es baja en la muestra, hay trimestres en los que la dirección del acarreo entre el peso chileno y el dólar estadounidense y entre el peso y el euro cambia de positiva a negativa y viceversa.
} 
son mayormente utilizadas por estos inversionistas, que compran dólares. Posteriormente, mientras los choques de incertidumbre persistentes reducen los márgenes de financiamiento en los mercados financieros mundiales, los cambios observados en las posiciones a plazo de no residentes serán cada vez más tenidos en cuenta por los especuladores que revierten sus posiciones. Esto explica tanto el efecto positivo contemporáneo como el efecto negativo posterior.

Del cuadro 3 también se desprende que los aumentos en $F P N R_{t-1}$ predicen un cambio más pequeño en $F P N R_{t}$, lo que podría explicarse por la presencia de un mayor riesgo de desplome.

\section{Cuadro 3}

Sensibilidad mensual de posiciones y rentabilidades de las operaciones de acarreo respecto de los cambios en el índice de incertidumbre de la política económica

\begin{tabular}{lcccc}
\hline & $\Delta F P N R_{t}$ & $\Delta F P N R_{t+1}$ & $Z_{t}$ & $Z_{t+1}$ \\
\hline \multirow{2}{*}{$\Delta P U_{t} \times \operatorname{sign}\left(i_{t-1}^{*}-i_{t-1}\right)$} & $0,987^{\star \star \star}$ & $-1,325^{\star \star \star}$ & $5,25 \mathrm{e}-05^{\star \star \star}$ & $-0,000170^{\star \star \star}$ \\
\hline \multirow{2}{*}{$\Delta F P R_{t-1}$} & $(0,0433)$ & $(0,153)$ & $(1,74 \mathrm{e}-05)$ & $(6,43 \mathrm{e}-05)$ \\
\hline \multirow{2}{*}{$\Delta \log (\text { Copper })_{t-1}$} & $-0,207^{\star \star \star}$ & $-0,0686^{\star \star \star}$ & & \\
\hline & $(0,00250)$ & $(0,00494)$ & & \\
\cline { 2 - 5 }$B C C H_{t}$ & $0,445^{\star}$ & $-0,809^{\star \star \star}$ & & $-0,000604$ \\
\hline Observaciones & $(0,244)$ & $(0,229)$ & & $(0,00311)$ \\
\hline $\mathrm{R}^{2}$ & $-25,00^{\star \star \star}$ & $47,55^{\star \star \star}$ & $-0,00364^{\star \star \star}$ & 179 \\
\hline
\end{tabular}

Fuente: Elaboración propia, sobre la base de información del Banco Central de Chile, datos de Bloomberg y Economic Policy Uncertain Index [en línea] www.policyuncertain.com.

Nota: Panel con efectos fijos del país y datos mensuales, tercer mes de 2002-primer mes de 2012 para dólares estadounidenses y octavo mes de 2006-tercer mes de 2012 para euros. Los datos de las posiciones a plazo de no residentes incluyen únicamente contratos a término sin entrega. Tasa de interés mensual al comienzo del período $t$. Los errores estándar agrupados se muestran entre paréntesis: ${ }^{\star \star *} p<0,01 ;{ }^{* \star} p<0,05 ;{ }^{*} p<0,1$.

En la tercera y cuarta columna se indica la relación entre la incertidumbre y la rentabilidad esperada. La incertidumbre mundial se correlaciona de manera positiva con la rentabilidad de la inversión en el segundo mes tras un cambio en la incertidumbre, que desalienta las operaciones de acarreo. Considerando todos estos resultados juntos, podemos arribar a la siguiente conclusión: cuando baja la tolerancia al riesgo, los comerciantes revierten sus posiciones, lo que provoca una reducción en las posiciones a plazo de no residentes y en la rentabilidad $z_{t}$. La inclusión de la variable ficticia $\mathrm{BCCH}_{t}$ demuestra que es un importante factor explicativo tanto para la rentabilidad de las operaciones de acarreo como para los cambios en la variable de las posiciones a plazo de no residentes, aunque su impacto es corto.

La inclusión de una variable fundamental, como el precio del cobre, es relevante, pero no es robusta respecto de la inclusión de otros controles ${ }^{33}$. Dada la fuerte relación contemporánea entre el índice de incertidumbre de la política económica y el excedente de rentabilidad de las operaciones de acarreo, analizamos hasta qué punto los índices de incertidumbre mundial pueden predecir las rentabilidades futuras y aproximar cambios en las primas de riesgo (la base para la rentabilidad de las operaciones de acarreo). Consideramos la siguiente especificación de panel econométrica:

$$
z_{j t+1}=\beta_{1}\left(i_{j t}^{*}-i_{t}\right)+\beta_{2}\left(\Theta_{t} \times \operatorname{sign}\left(i_{j t-1}^{*}-i_{t-1}\right)\right)+\alpha_{j}+\varepsilon_{j t}
$$

\footnotetext{
${ }_{33}$ Por ejemplo, cuando se incluye el retardo de la operación de acarreo $\left(i_{t-1}^{*}-i_{t-1}\right)$ en la regresión, el precio del cobre no es significativo, mientras que los otros coeficientes estimados mantienen sus signos e importancia.
} 
donde $j$ es el país, $t$ es tiempo, $\alpha_{j}$ representa los efectos fijos del país (o la moneda) y $\varepsilon_{j t}$ es el término perturbador. $\Theta_{t}$ es el indicador de incertidumbre mundial o liquidez. Además de las medidas de incertidumbre mundial (el índice de incertidumbre de la política económica y el índice de volatilidad (VIX)), consideramos la medida de liquidez proporcionada por el margen entre el Tipo Interbancario de Oferta de Londres (LIBOR) y el "swap" de tasas de interés a un día (conocido como LOIS). En el cuadro 4 se presentan los resultados de las estimaciones de los efectos fijos.

\section{Cuadro 4}

Rentabilidad del tipo de cambio $z_{t}$ con regresión en las operaciones de acarreo $i_{t}^{*}-i_{t}$ y su interacción con el índice de volatilidad, el margen entre el Tipo Interbancario de Oferta de Londres (LIBOR) y el "swap" de tasas de interés a un día, y el índice de incertidumbre de la política económica

\begin{tabular}{|c|c|c|c|c|c|c|c|c|c|}
\hline $\begin{array}{l}\text { Excedente de } \\
\text { rentabilidad en }\end{array}$ & $z_{t+1}$ & $z_{t+2}$ & $z_{t+3}$ & $z_{t+1}$ & $z_{t+2}$ & $z_{t+3}$ & $z_{t+1}$ & $z_{t+2}$ & $z_{t+3}$ \\
\hline \multirow{2}{*}{$i_{t}^{*}-i_{t}$} & $1,073^{\star \star \star}$ & $0,924^{\star \star \star}$ & $0,724^{\star \star \star}$ & $1,077^{\star \star \star}$ & $0,882^{\star \star \star}$ & $0,694^{\star \star \star}$ & $1,121^{\star \star \star}$ & $0,974^{\star \star \star}$ & $0,721^{\star \star \star}$ \\
\hline & $(0,297)$ & $(0,244)$ & $(0,122)$ & $(0,293)$ & $(0,258)$ & $(0,110)$ & $(0,275)$ & $(0,209)$ & $(0,141)$ \\
\hline \multirow[b]{2}{*}{$\Delta V I X_{t} \times \operatorname{sign}\left(i_{t}^{*}-i_{t}\right)$} & $-0,000991$ & $-0,000326^{\star \star *}$ & $-0,000398$ & & & & & & \\
\hline & $(0,000753)$ & $(0,000124)$ & $(0,000376)$ & & & & & & \\
\hline \multirow{2}{*}{$\Delta \operatorname{LOIS}_{t} \times \operatorname{sign}\left(i_{t}^{*}-i_{t}\right)$} & & & & $-0,0147^{\star \star}$ & $-0,0222^{\star \star \star}$ & $-0,0100^{\star \star \star *}$ & & & \\
\hline & & & & $(0,00739)$ & $(0,00798)$ & $(0,00140)$ & & & \\
\hline \multirow[b]{2}{*}{$\Delta E P U_{t} \times \operatorname{sign}\left(i_{t}^{*}-i_{t}\right)$} & & & & & & & $-0,000116^{\star \star \star}$ & $-0,000154$ & $-1,15 e-05$ \\
\hline & & & & & & & $(2,23 e-05)$ & $(0,000163)$ & $(9,92 e-05)$ \\
\hline Observaciones & 236 & 234 & 232 & 236 & 234 & 232 & 236 & 234 & 232 \\
\hline R cuadrado & 0,147 & 0,052 & 0,042 & 0,091 & 0,116 & 0,043 & 0,073 & 0,066 & 0,028 \\
\hline
\end{tabular}

Fuente: Elaboración propia, sobre la base de información del Banco Central de Chile, datos de Bloomberg y Economic Policy Uncertain Index [en línea] www.policyuncertain.com.

Nota: Las regresiones de panel con efectos fijos del país y datos mensuales son para el período entre el tercer mes de 2002 y el primer mes de 2012. Los datos son para dólares estadounidenses y euros. El índice de volatilidad (VIX) mide el "apetito" de riesgo. El margen entre el Tipo Interbancario de Oferta de Londres (LIBOR) y el "swap" de tasas de interés a un día (LOIS) es una medida de liquidez internacional, al tiempo que el índice de incertidumbre de la política económica es una medida de incertidumbre económica y política. Los índices VIX, LOIS y de incertidumbre de la política económica corresponden a la observación final para cada trimestre. Los errores estándar agrupados se muestran entre paréntesis: ${ }^{* \star} p<0,01 ;{ }^{* \star} p<0,05 ;{ }^{*} p<0,1$.

Un resultado notable es la confirmación del efecto de la incertidumbre sobre las rentabilidades, un efecto robusto en las diferentes medidas de la incertidumbre mundial ${ }^{34}$. El efecto también se muestra persistente a lo largo del tiempo. Un aumento de la incertidumbre en $t$ tiene un impacto negativo en la rentabilidad en el mismo trimestre y en los siguientes dos trimestres, aunque el impacto se vuelve no significativo con el correr del tiempo. La incertidumbre general, por tanto, es un importante predictor de la rentabilidad, al tiempo que estos efectos son relevantes en el corto plazo. Por lo tanto, los datos coinciden con la hipótesis de Brunnermeier y Pedersen (2009).

\footnotetext{
${ }^{34}$ En el cuadro A1.1 del anexo se muestran los resultados usando el índice VIX en lugar del índice de incertidumbre de la política económica como indicador de la incertidumbre.
} 


\section{4. ¿La actividad de las operaciones de acarreo se concentra más en los contratos de corta o de larga duración?}

Una de las ventajas de las fuentes de datos utilizadas en este estudio es que nos permiten obtener información detallada sobre los contratos a término sin entrega que generalmente no está disponible en otras economías o mercados. En particular, podemos clasificar las transacciones de los no residentes (las cantidades hipotéticas de los contratos a término sin entrega) en virtud de su duración. En esta sección, usamos estos datos para identificar la duración de los contratos respecto de los cuales las operaciones de acarreo están más activas.

En el cuadro 5 se presenta el efecto diferenciado de las operaciones de acarreo en las transacciones de contratos a término sin entrega suscritos por agentes no residentes en virtud de su duración. Una estrategia de inversión de operaciones de acarreo debe implicar la adopción de posiciones más largas por parte de los especuladores tras un aumento de los diferenciales de la tasa de interés. Como se muestra en el cuadro 5, para las operaciones a corto plazo ( $<1$ mes), la relación entre la operación de acarreo y las posiciones a plazo de no residentes (la variable dependiente) no es estadísticamente significativa. A mediano plazo (para contratos que van de un mes a un año), no obstante, observamos que la operación de acarreo tiene una importante correlación con las posiciones a plazo de no residentes, lo que se ajusta a los datos y análisis presentados en esta y otras publicaciones (Ichiue y Koyama, 2011). También observamos que el signo que acompaña al coeficiente de la operación de acarreo se revierte para duraciones más largas, lo que confirma que la actividad especulativa se concentra en los contratos de duración media.

\section{Cuadro 5}

Posiciones a plazo de comerciantes no residentes, por plazo de los contratos a término sin entrega de base, regresión basada en acarreo $i_{t-1}^{*}-i_{t-1}$

\begin{tabular}{lccccc}
\hline & \multicolumn{5}{c}{ Posiciones a plazo de no residentes desagregadas por el plazo del contrato } \\
\cline { 2 - 6 } & 7 días & 8 a 30 días & 31 a 180 días & 181 a 365 días & $>365$ días \\
\hline$i_{t-1}^{*}-i_{t-1}$ & 1,837 & $-2,381$ & $90,495^{\star *}$ & $72,365^{\star \star *}$ & $-50,315^{*}$ \\
\hline Observaciones & $(1,495)$ & $(10,656)$ & $(44,102)$ & $(24,934)$ & $(27,207)$ \\
\hline $\mathrm{R}^{2}$ & 333 & 119 & 40 & 40 & 40 \\
\hline
\end{tabular}

Fuente: Elaboración propia, sobre la base de información del Banco Central de Chile.

Nota: Las regresiones de mínimos cuadrados ordinarios (OLS) son para dólares estadounidenses para el período que va del primer mes de 2002 al primer mes de 2012. Los datos para contratos de siete días se encuentran disponibles desde 2005 en adelante. Las posiciones a plazo de no residentes se expresan en miles de millones de dólares estadounidenses. Los diferenciales de la tasa de interés son para 7, 30, 180 y 360 días, respectivamente (datos semanales, mensuales y trimestrales), y los últimos se derivan de las tasas a 180 días. Los diferenciales de la tasa de interés que se muestran en la primera y en la segunda columna son para el comienzo de la semana/el mes. En la tercera y la quinta columna, los diferenciales de la tasa de interés corresponden al comienzo del trimestre. Para los contratos de más de un año de duración, los diferenciales de la tasa de interés se basan en tasas de interés a un año. Para los pesos chilenos se usa el tope de interés preferencial, mientras que para los dólares estadounidenses se usa el Tipo Interbancario de Oferta de Londres (LIBOR). Los errores estándar robustos se muestran entre paréntesis: ${ }^{* \star} p<0,01 ;{ }^{* \star} p<0,05 ;{ }^{*} p<0,1$. 


\section{Conclusiones}

En este documento hemos presentado datos sobre el uso, por parte de inversionistas extranjeros, de estrategias de inversión de operaciones de acarreo de divisas en las que intervienen el peso chileno y divisas de otras economías desarrolladas; el uso de estas estrategias ha sido favorecido por los grandes diferenciales de la tasa de interés entre estas monedas observados en los últimos años. Especialmente en períodos de gran incertidumbre mundial, esto ha tenido un gran impacto en el tipo de cambio nominal, que ha atravesado numerosos episodios de turbulencia. Mediante el empleo de distintas especificaciones econométricas, mostramos que un factor explicativo importante y robusto en la distribución de los cambios diarios en el tipo de cambio es la posición a plazo de no residentes en el mercado local. De conformidad con la interpretación de la relación entre el coeficiente de asimetría de la distribución y las posiciones en el mercado de futuros de dichos inversionistas, también observamos que el riesgo de desplome de la moneda hace que los inversionistas se abstengan de tomar posiciones que conducirían a la restauración de la paridad de tasas. Además, mostramos que un incremento en el riesgo global o el nivel de aversión al riesgo -medido por índices como el VIX, el LOIS o el índice de incertidumbre de la política económica- coincide con reducciones en las posiciones a plazo de no residentes y una menor rentabilidad de las operaciones de acarreo (prima de riesgo).

Los datos de este estudio también revelan que las posiciones a plazo de no residentes deben agregarse al análisis cuando se evalúan los factores que desestabilizan el tipo de cambio a corto plazo. La variable de las posiciones a plazo de no residentes es adecuada para explicar los notorios desajustes recientes en el tipo de cambio, identificados por Wu (2013). También recomendamos considerar el coeficiente de asimetría como un indicador de turbulencia en el tipo de cambio. Esta variable ofrece información relevante que no es captada por otros indicadores habitualmente utilizados, como la desviación estándar.

Desde el punto de vista de la política monetaria, el reciente y rápido desarrollo de las operaciones de acarreo en el caso del peso chileno es un factor que, junto con otros eventos y escenarios económicos, puede conducir a una situación en la cual los encargados de formular las políticas deben enfrentarse a una compensación entre el control de la inflación y la generación de riesgos vinculados a las divisas en los balances generales del sector real. En este contexto, los aumentos en la tasa de política destinados a frenar la inflación podrían incentivar las operaciones de acarreo, lo que generaría más presión inflacionaria. Este es un riesgo que los encargados de formular las políticas deben tomar en cuenta durante los períodos marcados por grandes diferenciales de la tasa de interés entre el peso chileno y otras divisas.

\section{Bibliografía}

Ahumada, A. y J. Selaive (2007), "Desarrollo del mercado de derivados cambiarios en Chile", Revista de Análisis Económico, vol. 22, № 1.

Alfaro, L. y F. Kanczuk (2013), "Carry trade, reserve accumulation, and exchange-rate regimes", NBER Working Paper Series, № 19098, Cambridge, Massachusetts, National Bureau of Economic Research.

Anzuini, A. y F. Fornari (2011), "Macroeconomics determinants of carry trade activity", Economic Working Papers, No 817, Banco de Italia.

Bacchetta, P. y E. van Wincoop (2010), "Infrequent portfolio decisions: a solution to the forward discount puzzle", American Economic Review, vol. 100, №3, Nashville, Tennessee, American Economic Association.

Baker, S., N. Bloom y S. Davis (2015), "Measuring economic policy uncertainty", NBER Working Paper Series, N 21633, Cambridge, Massachusetts, National Bureau of Economic Research [en línea] www. policyuncertainty.com/media/BakerBloomDavis.pdf. 
Banco Central de Chile (s/f), "Manual de procedimientos y formularios de información del Compendio de Normas de Cambios Internacionales" [en línea] http://www.bcentral.cl/es/faces/pfinanciera/manualprocedimientos?_ afrLoop $=1343102542531642$ \&_afrWindowMode $=0$ \&_afrWindowld =null\#! $\% 40 \% 40 \% 3 F_{-}$ afrWindowld\%3Dnull\%26_afrLoop\%3D1343102542531642\%26_afrWindowMode\%3D0\%26_adf. ctrl-state\%3D1bb09id9aa_4.

Bekaert, G. y R.J. Hodrick (1992), "Characterizing predictable components in excess return on equity and foreign exchange markets", Journal of Finance, vol. 47, № 2, Wiley.

BPI (Banco de Pagos Internacionales) (2013), Statistical Release. OTC Derivatives Statistics at End-June 2013 [en línea] http://www.bis.org/publ/otc_hy1311.pdf.

Brunnermeier, M.K. y L.H. Pedersen (2009), "Market liquidity and funding liquidity", Review of Financial Studies, vol. 22, $N^{\circ}$ 6, Oxford University Press.

Brunnermeier, M.K., S. Nagel y L.H. Pedersen (2008), "Carry trades and currency crashes", NBER Macroeconomics Annual 2008, vol. 23, Cambridge, Massachusetts, National Bureau of Economic Research.

Burnside, C. y otros (2010), "Do peso problems explain the returns to the carry trade", The Review of Financial Studies, vol. 24, № 3, Oxford University Press.

Engel, C. (1996), "The forward discount anomaly and the risk premium: a survey of recent evidence", Journal of Empirical Finance, vol. 3, № 2, Amsterdam, Elsevier.

Fama, E. (1984), "Forward and spot exchange rates", Journal of Monetary Economics, vol. 14, № 3, Amsterdam, Elsevier.

Gromb, D. y D. Vayanos (2010), "Limits of arbitrage", Annual Review of Financial Economics, vol. 2, № 1.

Gyntelberg, J. y E. Remolona (2007), "Risk in carry trades: a look at target currencies in Asia and the Pacific", BIS Quarterly Review, Banco de Pagos Internacionales, diciembre.

Hodrick, R.J. (1987), The Empirical Evidence on the Efficiency of Forward and Futures Foreign Exchange Markets, Harwood Academic Publishers.

Hutchison, M. y V. Sushko (2013), "Impact of macro-economic surprises on carry trade activity", Journal of Banking and Finance, vol. 37, № 4, Amsterdam, Elsevier.

Ichiue, H. y K. Koyama (2011), "Regime switches in exchange rate volatility and uncovered interest parity", Journal of International Money and Finance, vol. 30, $\mathrm{N}^{\circ} 7$, Amsterdam, Elsevier.

Jurek, J. (2014), "Crash-neutral currency carry trades", Journal of Financial Economics, vol. 113, № 3, Amsterdam, Elsevier.

Lustig, H., N. Roussanov y A. Verdelhan (2008), "Common risk factors in currency markets", NBER Working Paper Series, N 14082, Cambridge, Massachusetts, National Bureau of Economic Research.

Mitchell, M., L. Pedersen y T. Pulvino (2007), "Slow moving capital", American Economic Review, vol. 97, $N^{\circ}$ 2, Nashville, Tennessee, American Economic Association.

Plantin, G. y H.S. Shin (2011), "Carry trades, monetary policy and speculative dynamics", CEPR Discussion Papers, No 8224.

Salinas, J. y J. Villena (2014), "Mercado cambiario chileno, una comparación internacional: 1998 a 2013", Estudios Económicos Estadísticos, № 106, Santiago, Banco Central de Chile.

Wu, Y. (2013), "What explains movements in the peso/dollar exchange rate?", IMF Working Paper, N WP/13/171, Washington, D.C., Fondo Monetario Internacional. 


\section{Anexo A1}

\section{Gráfico A1.1}

Sección transversal de diferenciales de asimetría empírica y tasa de interés a tres meses, primer trimestre de 2002-primer trimestre de 2012

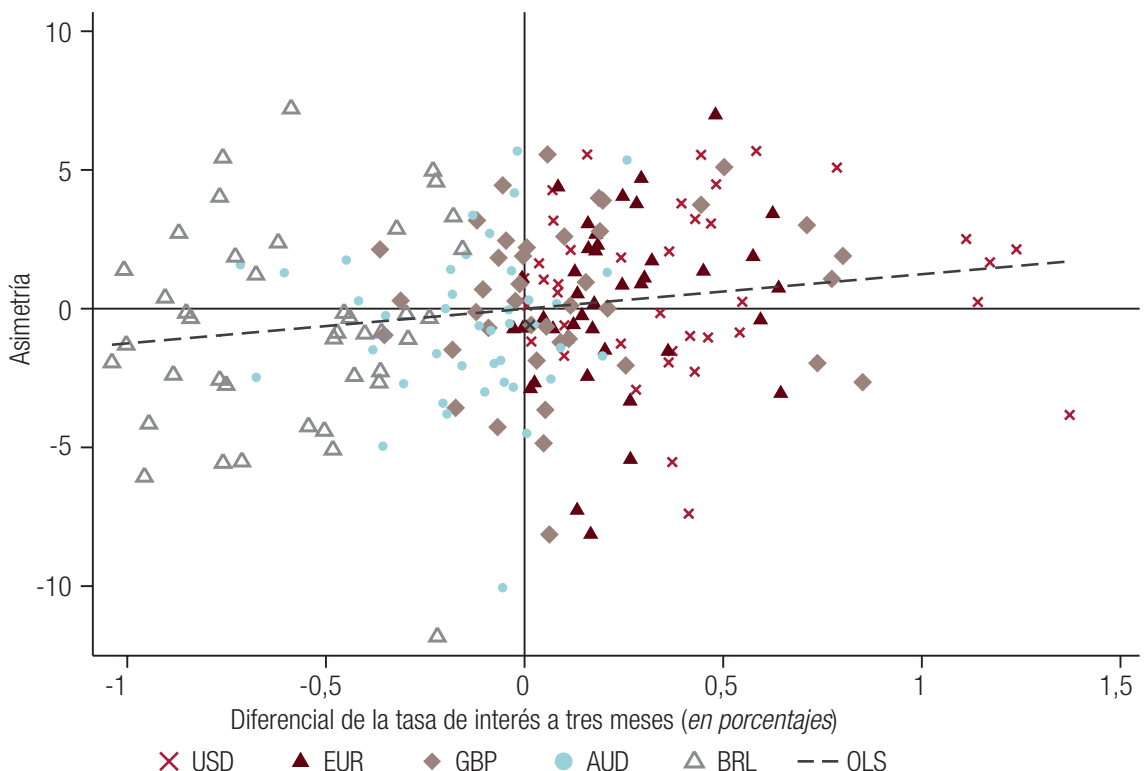

Fuente: Elaboración propia, sobre la base de información del Banco Central de Chile.

Nota: USD: Dólares estadounidenses; EUR: Euros; GBP: Libras esterlinas; AUD: Dólares australianos; BRL: Reales brasileños; OLS: Mínimos cuadrados ordinarios.

\section{Gráfico A1.2}

Sección transversal de diferenciales de rentabilidad empírica y tasa de interés a tres meses, primer trimestre de 2002-primer trimestre de 2012

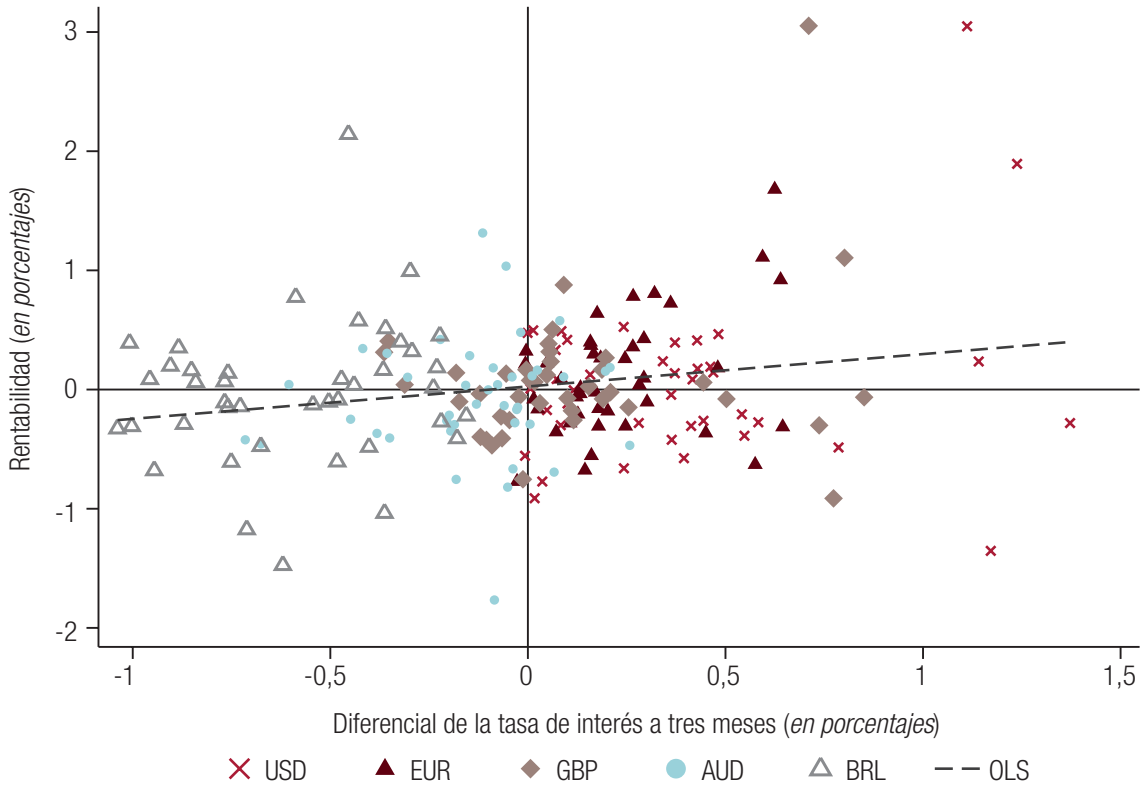

Fuente: Elaboración propia, sobre la base de información del Banco Central de Chile.

Nota: USD: Dólares estadounidenses; EUR: Euros; GBP: Libras esterlinas; AUD: Dólares australianos; BRL: Reales brasileños; OLS: Mínimos cuadrados ordinarios. 


\section{Gráfico A1.3}

Diferenciales de tasa de interés a tres meses (operación de acarreo) y volatilidad del tipo de cambio del peso chileno y el dólar estadounidense

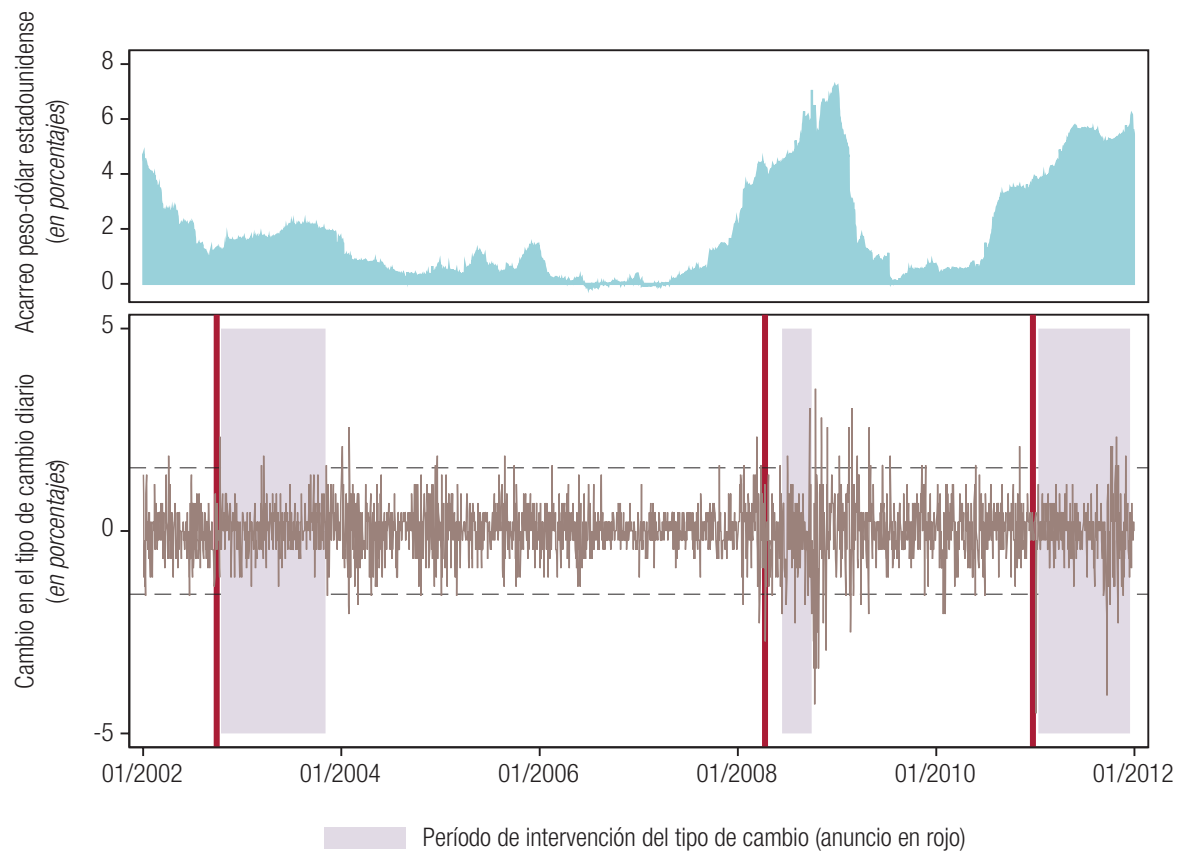

Fuente: Elaboración propia, sobre la base de información del Banco Central de Chile.

Nota: Las líneas rojas representan anuncios del banco central de que intervendría en el mercado de divisas. Las áreas sombreadas marcan los períodos en que esas intervenciones se concretaron. Las líneas punteadas en el gráfico inferior corresponden a dos bandas de desviación estándar (muestra 2002-2012).

\section{Gráfico A1.4}

Índice de incertidumbre de la política económica, primer mes de 2002-primer mes de 2012

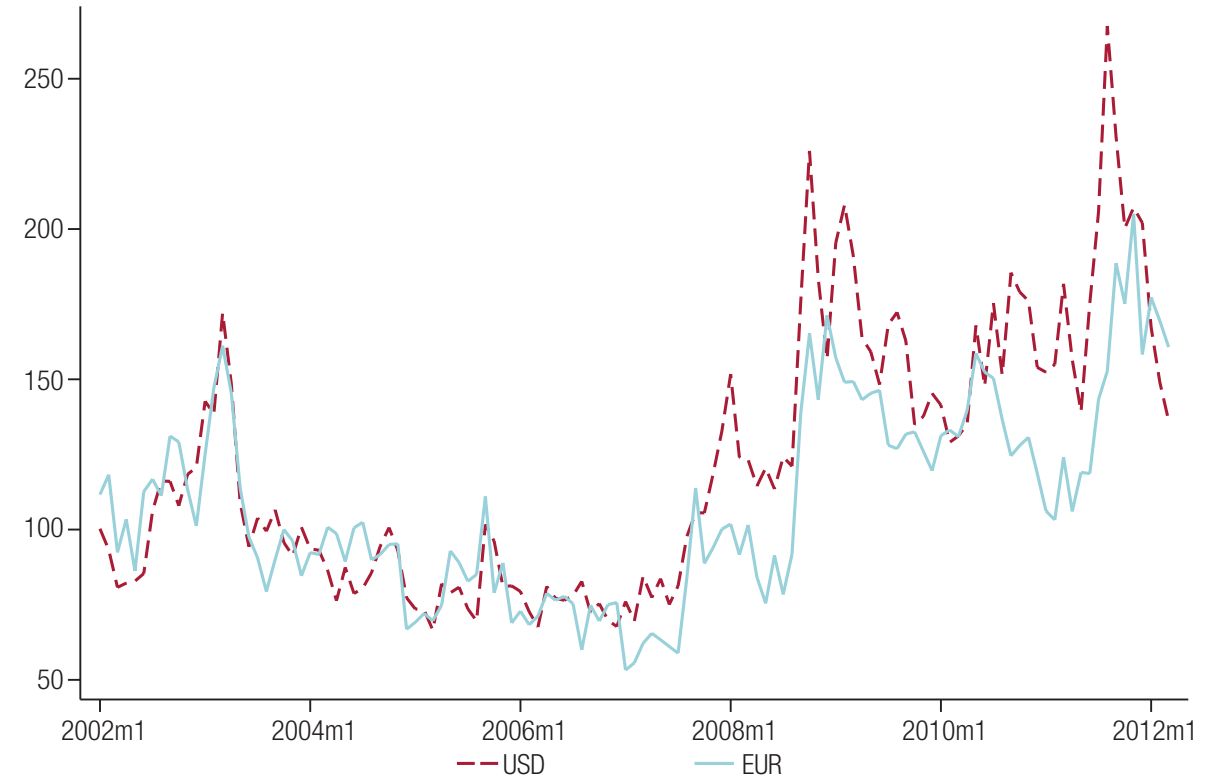

Fuente: S. Baker, N. Bloom y S. Davis, "Measuring economic policy uncertainty", NBER Working Paper Series, N 21633, Cambridge, Massachusetts, National Bureau of Economic Research, 2015 [en línea] www.policyuncertainty.com/ media/BakerBloomDavis.pdf.

Nota: USD: Dólares estadounidenses; EUR: Euros. 


\section{Cuadro A1.1}

Sensibilidad mensual de posiciones de las operaciones de acarreo y rentabilidades respecto de los cambios en el índice de volatilidad

\begin{tabular}{|c|c|c|c|c|}
\hline & $\begin{array}{c}(1) \\
\Delta F P N R_{t}\end{array}$ & $\begin{array}{c}(2) \\
\Delta F P N R_{t+1}\end{array}$ & $\begin{array}{c}(3) \\
z_{t}\end{array}$ & $\begin{array}{l}(4) \\
z_{t+1}\end{array}$ \\
\hline \multirow{2}{*}{$\Delta V I X_{t} \times \operatorname{sign}\left(i_{t-1}^{*}-i_{t-1}\right)$} & $-12,48$ & $-1,203$ & $-6,46 e-06$ & $-0,00106$ \\
\hline & $(11,82)$ & $(1,396)$ & $(0,000143)$ & $(0,000806)$ \\
\hline \multirow{2}{*}{$\triangle F P N R_{t-1}$} & $-0,190^{\star \star *}$ & $-0,0718^{* * *}$ & & \\
\hline & $(0,0106)$ & $(0,00567)$ & & \\
\hline \multirow{2}{*}{$\Delta \log (\text { Copper })_{t-1}$} & $0,311^{\text {***}}$ & $-0,824^{\text {***}}$ & & \\
\hline & $(0,0614)$ & $(0,256)$ & & \\
\hline \multirow{2}{*}{$\mathrm{BCCH}_{t}$} & $-64,62$ & $54,48^{\star \star \star}$ & $-0,00408^{\star \star \star}$ & $-0,00223$ \\
\hline & $(45,83)$ & $(9,703)$ & $(0,000141)$ & $(0,00721)$ \\
\hline Observaciones & 179 & 175 & 183 & 179 \\
\hline $\mathrm{R}^{2}$ & 0,060 & 0,011 & 0,004 & 0,120 \\
\hline
\end{tabular}

Fuente: Elaboración propia, sobre la base de información del Banco Central de Chile y datos de Bloomberg.

Nota: En el panel se muestran los efectos fijos del país y datos mensuales para el período del tercer mes de 2002-primer mes de 2012 para dólares estadounidenses y del octavo mes de 2006 al tercer mes de 2012 para euros. Los datos sobre las posiciones a plazo de no residentes solo incluyen contratos a término sin entrega. Las tasas de interés mensuales se muestran al comienzo del período $t$. Los errores estándar agrupados se muestran entre paréntesis: ${ }^{* \star *} p<0,01 ;{ }^{* *} p<0,05 ;{ }^{*} p<0,1$. 